Supporting information for:

\title{
From Milligram to Kilogram Manufacture of AZD4573: Making it Possible by Application of Enzyme-, Iridium-, and Palladium-Catalyzed Key Transformations
}

Staffan Karlsson, ${ }^{a}$ Helen Benson, ${ }^{b}$ Calum Cook, ${ }^{b}$ Gordon Currie, ${ }^{b}$ Jerome Dubiez, ${ }^{b}$ Hans

Emtenäs, ${ }^{a}$ Janet Hawkins, ${ }^{c}$ Rebecca Meadows, ${ }^{d}$ Peter D. Smith, ${ }^{b}$ Jeffrey Varnes ${ }^{e}$

${ }^{a}$ Early Chemical Development, Pharmaceutical Sciences, Biopharmaceuticals R\&D, AstraZeneca, Gothenburg, Sweden

${ }^{b}$ Early Chemical Development, Pharmaceutical Sciences, Biopharmaceuticals R\&D, AstraZeneca, Macclesfield, United Kingdom

${ }^{\mathrm{c}}$ Medicinal Chemistry, Oncology R\&D, AstraZeneca, Cambridge, United Kingdom

${ }^{\mathrm{d} C h e m i c a l}$ Development, Pharmaceutical Technology \& Development, Operations, AstraZeneca, Macclesfield, United Kingdom

${ }^{\mathrm{e}}$ Medicinal Chemistry, Oncology R\&D, AstraZeneca, Boston, MA, USA

\section{staffan.po.karlsson@astrazeneca.com}

Content:

S 1-2: Title and contents

S 3: Table S1 - initial screening results for Ir-catalyzed borylation of 4

S 4-6: Procedure for kg-scale preparation of compound 2 and associated analytical data

S 7-9: Procedure for kg-scale preparation of compound 3 and associated analytical data 
S 10-12: Procedure for kg-scale preparation of compound 4 and associated analytical data

S 13: ${ }^{1} \mathrm{H}$ NMR spectrum for crude compound 5a

S 14-15: ${ }^{1} \mathrm{H}$ NMR, ${ }^{13} \mathrm{C}$ NMR spectra for compound 6

S 16-17: HPLC chromatogram for compound 6

S 18: ${ }^{1} \mathrm{H}$ NMR assay spectrum for compound 8

S 19: Analytical testing summary report for compound 15

S 20-25: ${ }^{1} \mathrm{H}$ NMR spectrum, ${ }^{1} \mathrm{H}$ NMR assay spectrum and report for compound $\mathbf{1 5}$

S 26-27: ${ }^{1} \mathrm{H}$ NMR, ${ }^{13} \mathrm{C}$ NMR spectra for compound 16

S 28: ${ }^{1} \mathrm{H}$ NMR assay spectrum for compound $\mathbf{1 6}$

S 29-30: ${ }^{1} \mathrm{H}$ NMR, ${ }^{13} \mathrm{C}$ NMR spectra for compound AZD4573 
Table S1 - initial screening results for Ir-catalyzed borylation of 4:

\begin{tabular}{|c|c|c|c|c|c|c|c|c|}
\hline \multirow{2}{*}{ Entry } & \multirow{2}{*}{$\begin{array}{l}{[\mathrm{Ir}]-\mathrm{cat}} \\
(\mathrm{mol} \%)\end{array}$} & \multirow{2}{*}{ ligand $^{b}$} & \multirow{2}{*}{$\mathrm{mol} \%$} & \multirow{2}{*}{ solvent } & \multirow{2}{*}{$\begin{array}{l}\text { Tem } \\
\text { p. } \\
\left({ }^{\circ} \mathrm{C}\right)\end{array}$} & \multicolumn{3}{|c|}{$\begin{array}{c}\text { Conversion of } 4 \text { to } 6(\% \\
\text { UPLC) }\end{array}$} \\
\hline & & & & & & 1 hour & 3 hours & 23 hours \\
\hline 1 & 5 & phen & 5 & hexane & 60 & 38 & - & - \\
\hline 2 & 5 & dtb-bipy & 5 & hexane & 60 & 53 & - & - \\
\hline 3 & 5 & tmphen & 5 & hexane & 60 & 65 & - & - \\
\hline 4 & 5 & dtb-bipy & 5 & THF & 60 & 74 & - & - \\
\hline 5 & 5 & tmphen & 5 & THF & 60 & 68 & - & - \\
\hline 6 & 5 & tmphen & 5 & MTBE & 60 & 71 & - & - \\
\hline 7 & 5 & tmphen & 5 & iPrOAc & 60 & 94 & - & - \\
\hline 8 & 5 & tmphen & 5 & DMSO & 60 & 0 & - & - \\
\hline 9 & 5 & tmphen & 10 & THF & 60 & 78 & - & - \\
\hline 10 & 5 & tmphen & 5 & CPME & 60 & 69 & - & - \\
\hline 11 & 5 & tmphen & 5 & DMF & 60 & 7 & - & - \\
\hline
\end{tabular}

${ }^{\mathrm{a}}[\operatorname{Ir}(\mathrm{cod}) \mathrm{OMe}]_{2}(1-5 \mathrm{~mol} \%)$, ligands (4-10 mol\%), $\mathrm{B}_{2} \mathrm{pin}_{2}$ (1.5 eq.) and internal standard were charged to reaction vials in an inerted glovebox $\left(<5 \mathrm{ppm} \mathrm{O}_{2}\right.$ and $\left.<1 \mathrm{ppm} \mathrm{H}_{2} \mathrm{O}\right)$. Solvent $(0.85$ $\mathrm{mL})$ and $4(0.2 \mathrm{mmol}$ as a $1.86 \mathrm{M}$ solution in hexane) were then added and the vials sealed, stirred and heated for $1 \mathrm{hr} .{ }^{\mathrm{b}}$ phen $=$ phenanthroline, dtb-byp $=4,4^{\prime}$ '-di-tert-butyl-2,2'-bipyridyl, tmphen $=3,4,7,8$-tetramethylphenanthroline 
Procedure for $\mathrm{kg}$-scale preparation of compound $\mathbf{2}$

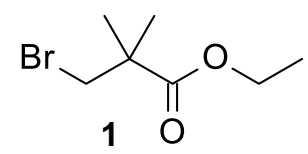

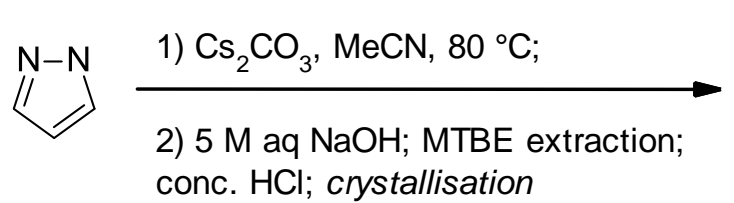

$60 \%$

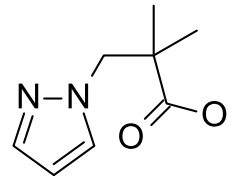

2

Step1: Acetonitrile $(202.2 \mathrm{~kg})$ was charged into a 500L glass-lined reactor and agitation commenced. Compound 1 (ethyl 3-bromo-2,2-dimethylpropanoate, $32.4 \mathrm{~kg}$ ) was added into the mixture at $15-30^{\circ} \mathrm{C}$ using a peristaltic pump. Pyrazole $(12.5 \mathrm{~kg})$ was then added and the mixture was stirred until all solid were dissolved. Cesium carbonate $(74.9 \mathrm{~kg})$ was added and the mixture was then heated to $78-85^{\circ} \mathrm{C}$ and stirred for 20 hours before the addition of additional pyrazole $(1.2 \mathrm{~kg})$ and cesium carbonate $(23.7 \mathrm{~kg})$. The reaction mixture was stirred for a further 6 hours.

Step 2: The mixture was cooled to $15-30{ }^{\circ} \mathrm{C}$ and then filtered using a stainless steel nutsche filter. The filter cake was rinsed twice with acetonitrile $(76.0 \mathrm{~kg}$ and $75.5 \mathrm{~kg})$ and the combined filtrate solutions were concentrated at $\mathrm{T} \leq 50{ }^{\circ} \mathrm{C}$ under reduced pressure $(\mathrm{P} \leq-0.08 \mathrm{MPa})$ until a volume of approximately $160 \mathrm{~L}$ was left. After concentration, the mixture was cooled to 15-30 ${ }^{\circ} \mathrm{C}$ and a solution of sodium hydroxide $(19.2 \mathrm{~kg})$ in purified water $(96.0 \mathrm{~kg})$ was added to the stirred mixture using a peristaltic pump. The mixture was heated to $40-50{ }^{\circ} \mathrm{C}$ and stirred for 3 hours until hydrolysis was complete. The mixture was then cooled to $15-30{ }^{\circ} \mathrm{C}$ before addition of methyl tert-butyl ether $(94.7 \mathrm{~kg})$. The mixture was stirred for 1 hour and settled for a further 1 hour before phase separation. The aqueous phase was further extracted by addition of methyl tert-butyl ether $(95.2 \mathrm{~kg})$ and the mixture was stirred for 1 hour and settled for 1 hour before phase separation. The aqueous phase was cooled to $0-10{ }^{\circ} \mathrm{C}$ and, maintaining the temperature at $0-10{ }^{\circ} \mathrm{C}$, concentrated hydrochloric acid $(57.2 \mathrm{~kg})$ was added to the mixture using a peristaltic pump, resulting in $\mathrm{pH} \mathrm{3-4} \mathrm{and} \mathrm{the} \mathrm{initiation} \mathrm{of} \mathrm{crystallization} \mathrm{in} \mathrm{the} \mathrm{solution.} \mathrm{The} \mathrm{mixture} \mathrm{was}$ stirred at $0-10{ }^{\circ} \mathrm{C}$ for 6 hours before filtration using a plastic-lined centrifuge. The resulting filter cake was rinsed twice with purified water $(96.7 \mathrm{~kg}$ and $96.8 \mathrm{~kg})$ and then oven-dried at $35-45{ }^{\circ} \mathrm{C}$ to provide compound 2 (2,2-dimethyl-3-(1H-pyrazol-1-yl)propanoic acid, $15.4 \mathrm{Kg}$, $59.9 \%$ yield) as a white solid (purity by HPLC, 100.0\%; Assay by QNMR, 99.6\%; water content by Karl-Fisher: $0.1 \%$ ). 
HPLC chromatogram of compound 2:

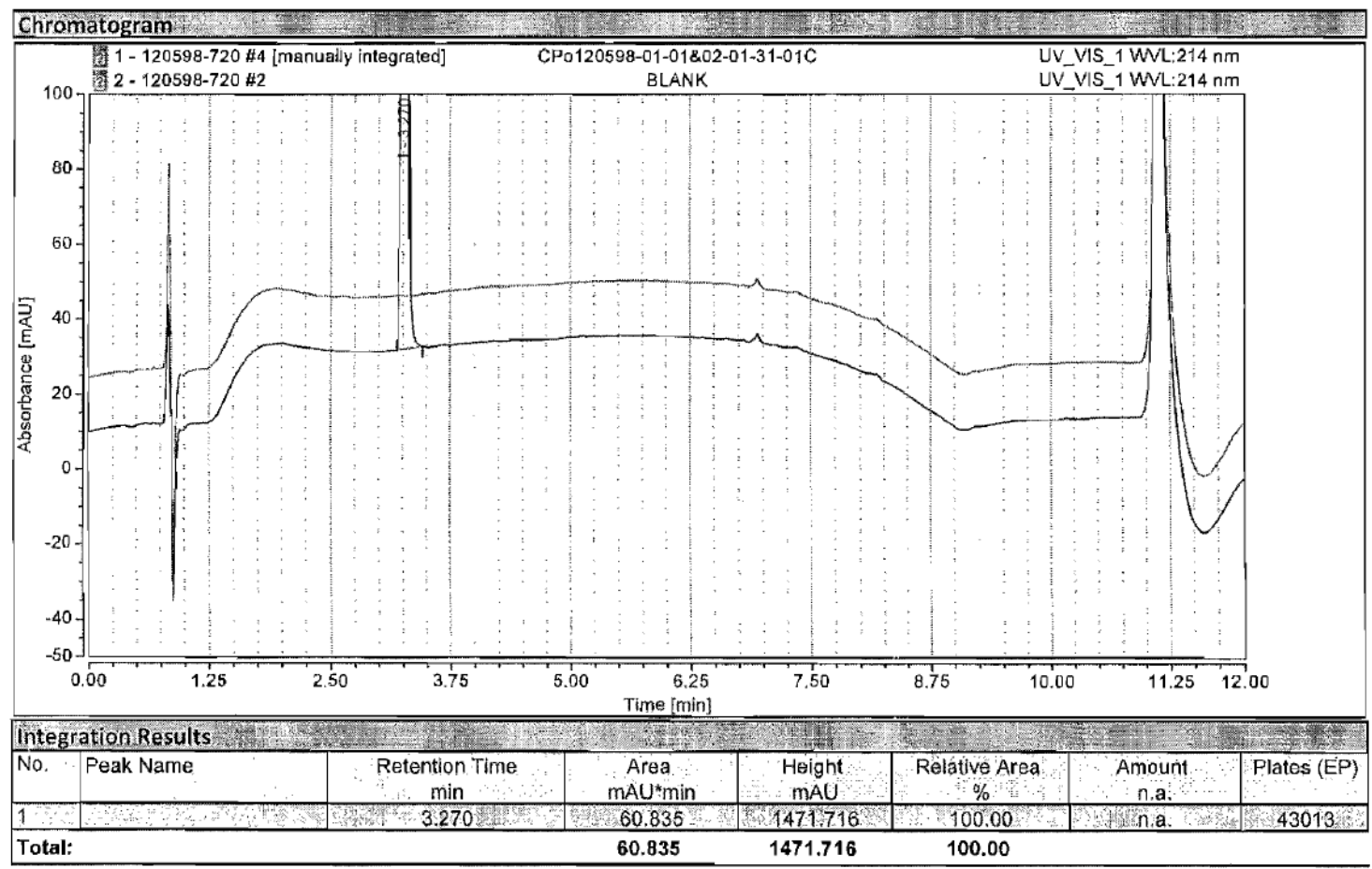

Quantitative ${ }^{1} \mathrm{H}$ NMR of compound 2:

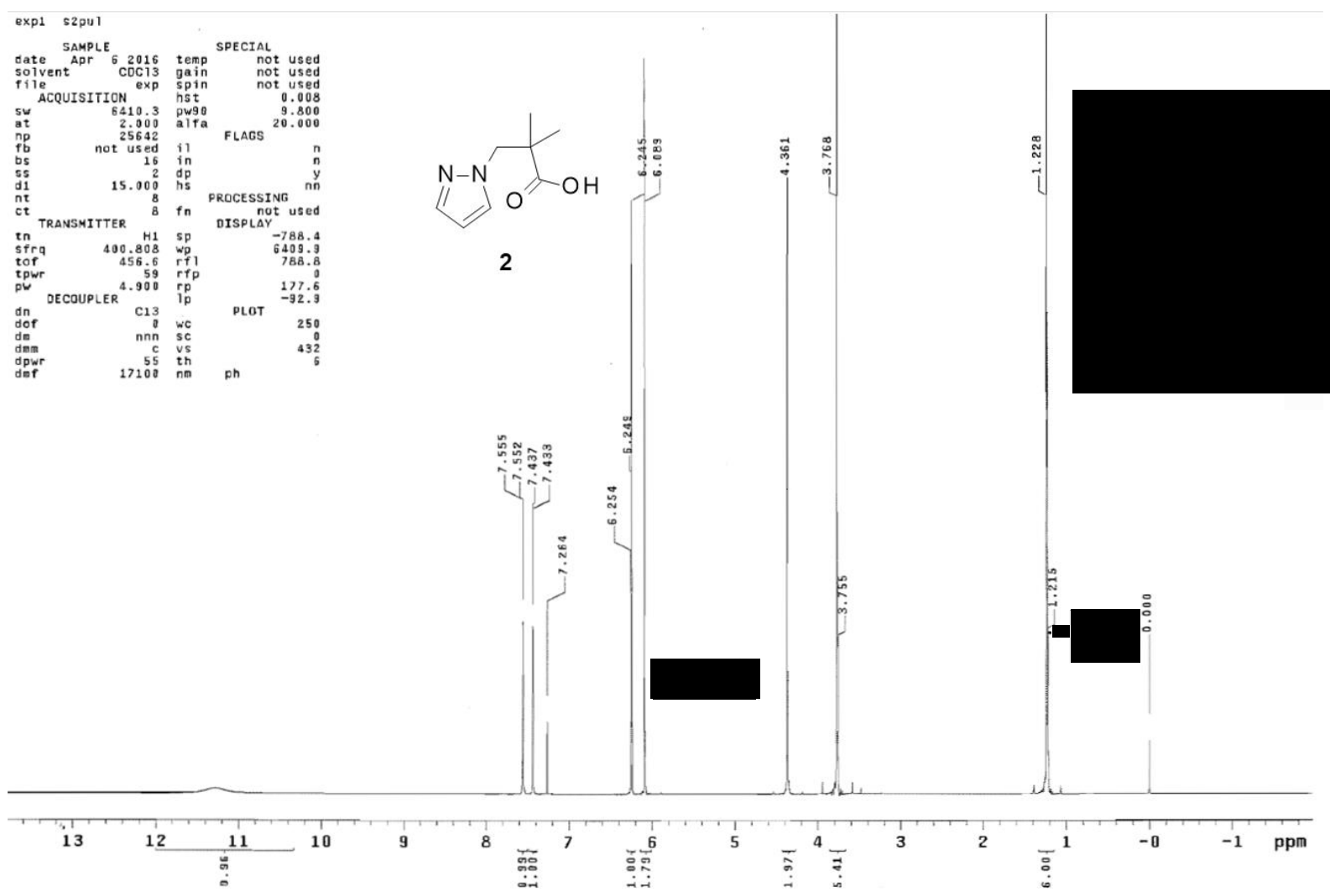




\begin{tabular}{|c|c|}
\hline Instrument & Varian $400 \mathrm{MHz}$ \\
\hline Solvent and concentration & $\mathrm{CDCl}_{3}$ \\
\hline Internal standard & $1,3,5$-trimethoxybenzene \\
\hline Nucleus and frequency in $\mathrm{MHz}$ & ${ }^{1} \mathrm{H}$ and $400.808 \mathrm{MHz}$ \\
\hline
\end{tabular}

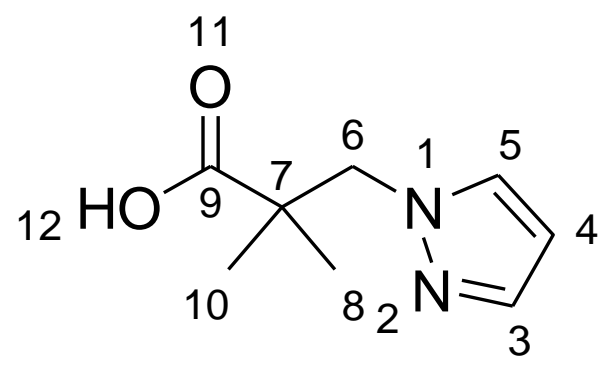

\begin{tabular}{|c|c|c|c|}
\hline${ }^{1} \mathrm{H}$ resonances $(\mathrm{ppm})$ & Number of $\mathrm{H}$ & Multiplicity & Atom \\
\hline$\sim 11.4$ & 1 & $\mathrm{~b}$ & 12 \\
\hline 7.55 & 1 & $\mathrm{~d}$ & 5 \\
\hline 7.44 & 1 & $\mathrm{~d}$ & 3 \\
\hline 6.25 & 1 & $\mathrm{t}$ & 4 \\
\hline 4.36 & 2 & $\mathrm{~s}$ & 6 \\
\hline 1.23 & 6 & $\mathrm{~s}$ & 8,10 \\
\hline
\end{tabular}

Note: $s=$ singlet,$d=$ doublet $t=$ triplet; $q=$ quartet,$m=$ multiplet,$d d=$ double doublet,$b=b r o a d$

\begin{tabular}{|c|c|}
\hline Other ${ }^{1} \mathrm{H}$ resonances $(\mathrm{ppm})$ & Comment \\
\hline 0.00 & $\mathrm{TMS}$ \\
\hline 7.26 & $\mathrm{CDCl}_{3}$ \\
\hline $6.09,3.71$ & 1,3,5-trimethoxybenzene \\
\hline
\end{tabular}


Procedure for $\mathrm{kg}$-scale preparation of compound $\mathbf{3}$

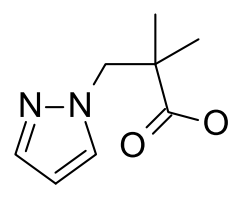

2

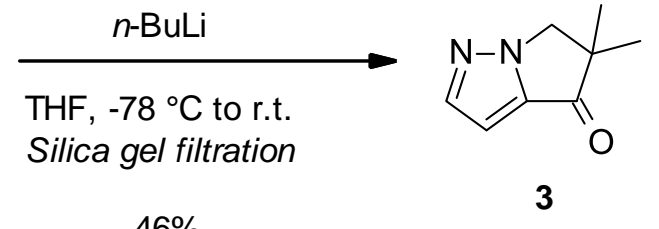

$46 \%$

Compound $2(14.6 \mathrm{~kg})$ was added to anhydrous tetrahydrofuran $(211.2 \mathrm{~kg}$, KF analysis $\leq 500$ $\mathrm{ppm})$ in a titanium reactor and the mixture was stirred at $15-25^{\circ} \mathrm{C}$ for 1 hour until the solid was dissolved. The mixture was cooled to below $-70{ }^{\circ} \mathrm{C}$ and $\mathrm{n}-\mathrm{BuLi}(2.5 \mathrm{M}$ solution in hexane, 89.1 L) was added to the mixture at a rate that maintained the reaction temperature below -45 ${ }^{\circ} \mathrm{C}$. The mixture was then heated to $15{ }^{\circ} \mathrm{C}$ and stirred for 4 hours until the reaction was complete.

The reaction mixture was transferred to a precooled $\left(0-5^{\circ} \mathrm{C}\right)$ solution of ammonium chloride $(36.8 \mathrm{~kg})$ in purified water $(147.1 \mathrm{~kg})$ at a rate that maintained the solution temperature below $10{ }^{\circ} \mathrm{C}$. The mixture was then heated to $25^{\circ} \mathrm{C}$, methyl tert-butyl ether $(66.1 \mathrm{~kg})$ was added and the mixture was stirred for 1 hour then settled for 1 hour before phase separation. The aqueous phase was extracted twice more with methyl tert-butyl ether $(66.4 \mathrm{~kg}$ and $64.9 \mathrm{~kg})$ at $25^{\circ} \mathrm{C}$. In each extraction, the mixture was stirred for 1 hour and settled for 1 hour before separation. The combined organic phase was washed using a solution of sodium chloride $(14.8 \mathrm{~kg})$ in purified water $(59.0 \mathrm{~kg})$ at $25{ }^{\circ} \mathrm{C}$ with the mixture stirred for 1 hour and settled for 1 hour before separation. Active carbon $(1.5 \mathrm{~kg})$ was added to the separated organic phase and the mixture was heated with stirring to $45^{\circ} \mathrm{C}$. The mixture was maintained at this temperature for 4 hours and then cooled to $25^{\circ} \mathrm{C}$. The mixture was filtered using a stainless steel nutsche filter which was preloaded with silica gel $(4.1 \mathrm{~kg})$ and the filter cake was rinsed twice with methyl tertbutyl ether $(32.6 \mathrm{~kg}$ and $32.6 \mathrm{~kg})$. The combined filtrate solution was concentrated at $\mathrm{T} \leq 35^{\circ} \mathrm{C}$ under reduced pressure $(\mathrm{P} \leq-0.08 \mathrm{MPa})$ to obtain compound 3 (5,5-dimethyl-5,6-dihydro- $4 \mathrm{H}$ pyrrolo[1,2-b]pyrazol-4-one, $11.3 \mathrm{~kg}, 46.2 \%$ yield) as a pale brown liquid (purity by HPLC, 91.9\%; Assay by QNMR: 53.1\%). 
HPLC chromatogram of compound 3 :

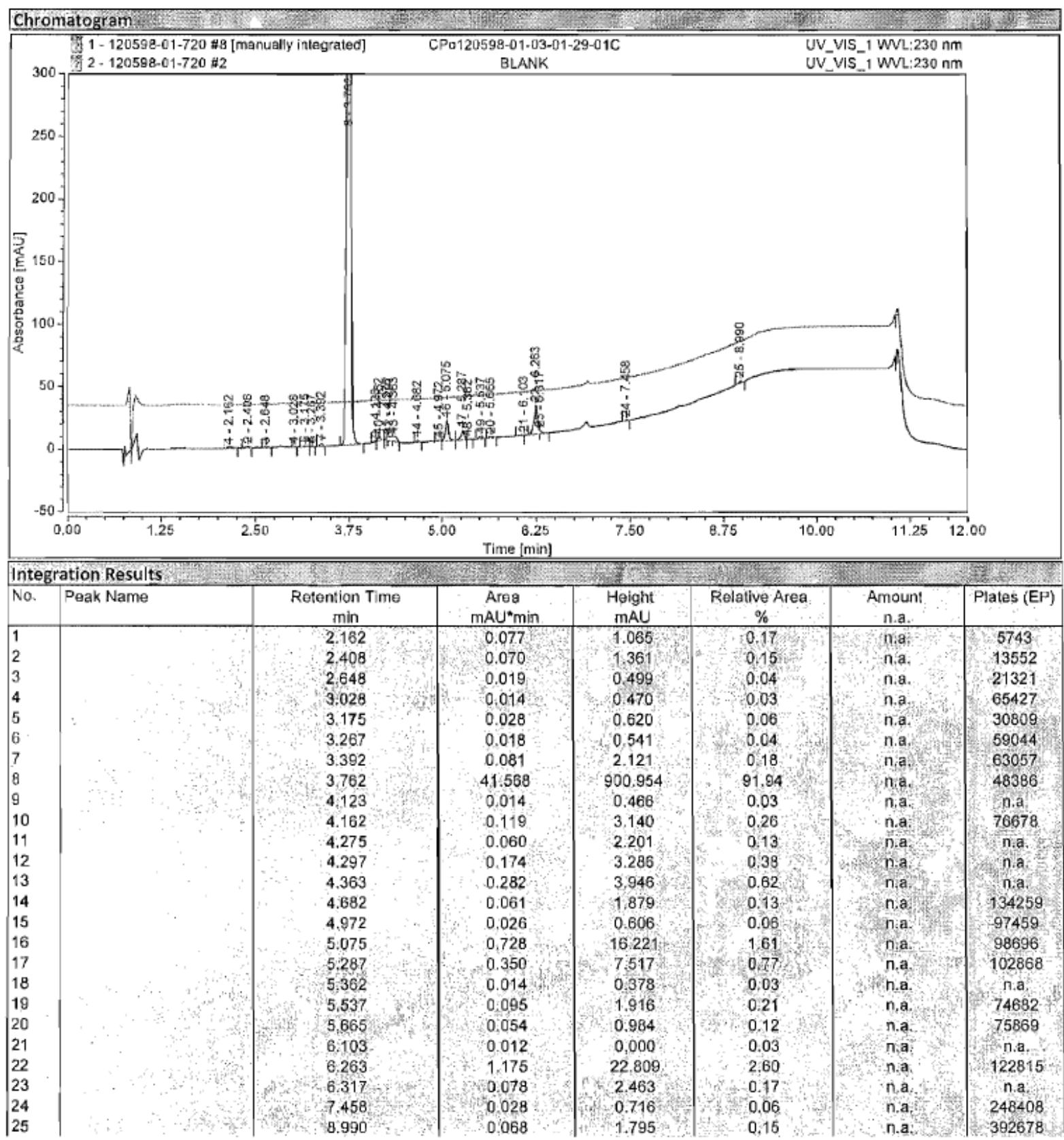


Quantitative ${ }^{1} \mathrm{H}$ NMR of compound 3:
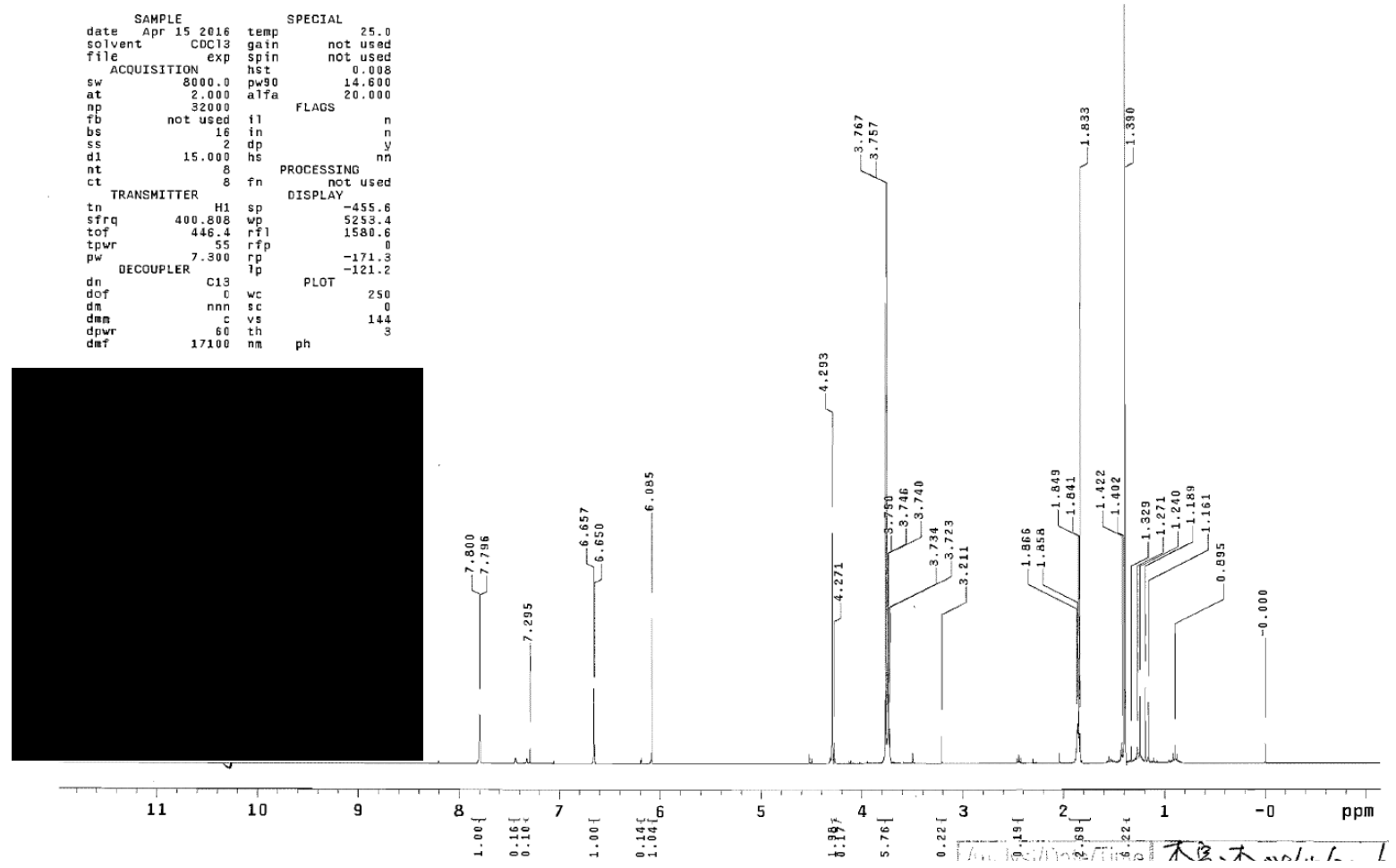

\begin{tabular}{|c|c|}
\hline Instrument & Varian $400 \mathrm{MHz}$ \\
\hline Solvent and concentration & $\mathrm{CDCl}_{3}$ \\
\hline Internal standard & $1,3,5$-trimethoxybenzene \\
\hline Nucleus and frequency in $\mathrm{MHz}$ & ${ }^{1} \mathrm{H}$ and $400.808 \mathrm{MHz}$ \\
\hline
\end{tabular}<smiles>CC1(C)Cn2nccc2C1=O</smiles>

\begin{tabular}{|c|c|c|c|}
\hline${ }^{1} \mathrm{H}$ resonances $(\mathrm{ppm})$ & Number of $\mathrm{H}$ & Multiplicity & Atom \\
\hline 7.80 & 1 & $\mathrm{~d}$ & 3 \\
\hline 6.65 & 1 & $\mathrm{~d}$ & 2 \\
\hline 4.29 & 2 & $\mathrm{~s}$ & 6 \\
\hline 1.40 & 6 & $\mathrm{~s}$ & 9,10 \\
\hline
\end{tabular}

Note: $s=$ singlet,$d=$ doublet $t=$ triplet $; q=$ quartet,$m=$ multiplet,$d d=$ double doublet,$b=b r o a d$

\begin{tabular}{|c|c|}
\hline Other ${ }^{1} \mathrm{H}$ resonances $(\mathrm{ppm})$ & Comment \\
\hline 0.00 & TMS \\
\hline 1.86 & unknown \\
\hline 7.26 & $\mathrm{CDCl}_{3}$ \\
\hline $6.09,3.75$ & $1,3,5$-trimethoxybenzene \\
\hline
\end{tabular}


Procedure for $\mathrm{kg}$-scale preparation of compound 4

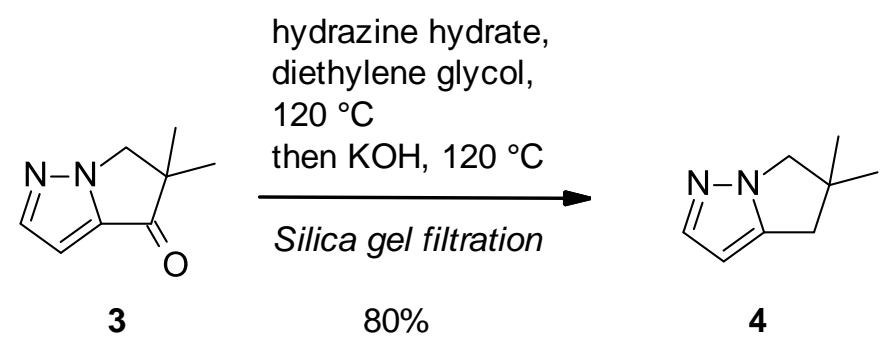

Compound $3(5.7 \mathrm{~kg}, 3.0 \mathrm{~kg}$ assay corrected $)$, diethylene glycol (33.6 kg) and hydrazine hydrate $(4.0 \mathrm{~kg})$ were charged into an $80 \mathrm{~L}$ glass reactor. The mixture was heated to $110-120{ }^{\circ} \mathrm{C}$ and stirred at this temperature for 4 hours, until HPLC analysis showed that compound 3 was present at $\leq 1 \%$ by area. The reaction mixture was then cooled to $100{ }^{\circ} \mathrm{C}$ before a $50 \%$ solution of potassium hydroxide $(3.9 \mathrm{~kg})$ in purified water $(3.9 \mathrm{~kg})$ was added to the reaction at a rate of $\sim 6 \mathrm{~kg}$ /hour. The temperature was adjusted back to $120^{\circ} \mathrm{C}$ and the reaction was stirred for a further 4 hours.

The reaction mixture was then cooled to $10{ }^{\circ} \mathrm{C}$ and adjusted to $\mathrm{pH} \sim 6$ through the addition of $6 \mathrm{M}$ hydrochloric acid solution $(24.5 \mathrm{~kg}$ ) [prepared using concentrated hydrochloric acid (15.3 $\mathrm{kg}$ ) and purified water $(15.3 \mathrm{~kg})]$, with the rate of addition of the $6 \mathrm{M}$ hydrochloric acid being such that the reaction temperature did not exceed $15{ }^{\circ} \mathrm{C}$. The reaction mixture was then extracted three times with methyl tert-butyl ether (each portion $11.1 \mathrm{~kg}$ ). After each addition of methyl tert-butyl ether the mixture was stirred for 30 minutes and left to settle for 30 minutes before separation of the phases. The organic phases were combined and washed with purified water $(12.0 \mathrm{~kg})$ then with a solution of sodium chloride $(3.0 \mathrm{~kg})$ in purified water $(12.0 \mathrm{~kg})$. Active carbon $(0.3 \mathrm{~kg})$ was added into the organic extract and this mixture was then heated to $45{ }^{\circ} \mathrm{C}$ for 3 hours. The mixture was filtered using a 10L vacuum filter flask which had been pre-loaded with silica gel $(3 \mathrm{~cm}$ bed height, $4.5 \mathrm{~kg})$. The filter cake was rinsed twice with methyl tert-butyl ether $(4.5 \mathrm{~kg}$ and $4.5 \mathrm{~kg})$ and the combined filtrates concentrated at $\leq 35{ }^{\circ} \mathrm{C}$ under reduced pressure $(\mathrm{P} \leq-0.08 \mathrm{MPa})$ until no more distillate was obtained. The residual mixture was cooled to $20{ }^{\circ} \mathrm{C}$ providing compound 4 (5,5-dimethyl-5,6-dihydro- $4 \mathrm{H}$ pyrrolo[1,2-b]pyrazole, $3.6 \mathrm{~kg}, 79.5 \%$ yield) as clear red solution (purity by HPLC, 91.9\%; assay by QNMR: 60.9\%). 
HPLC chromatogram of compound $\mathbf{4}$ :

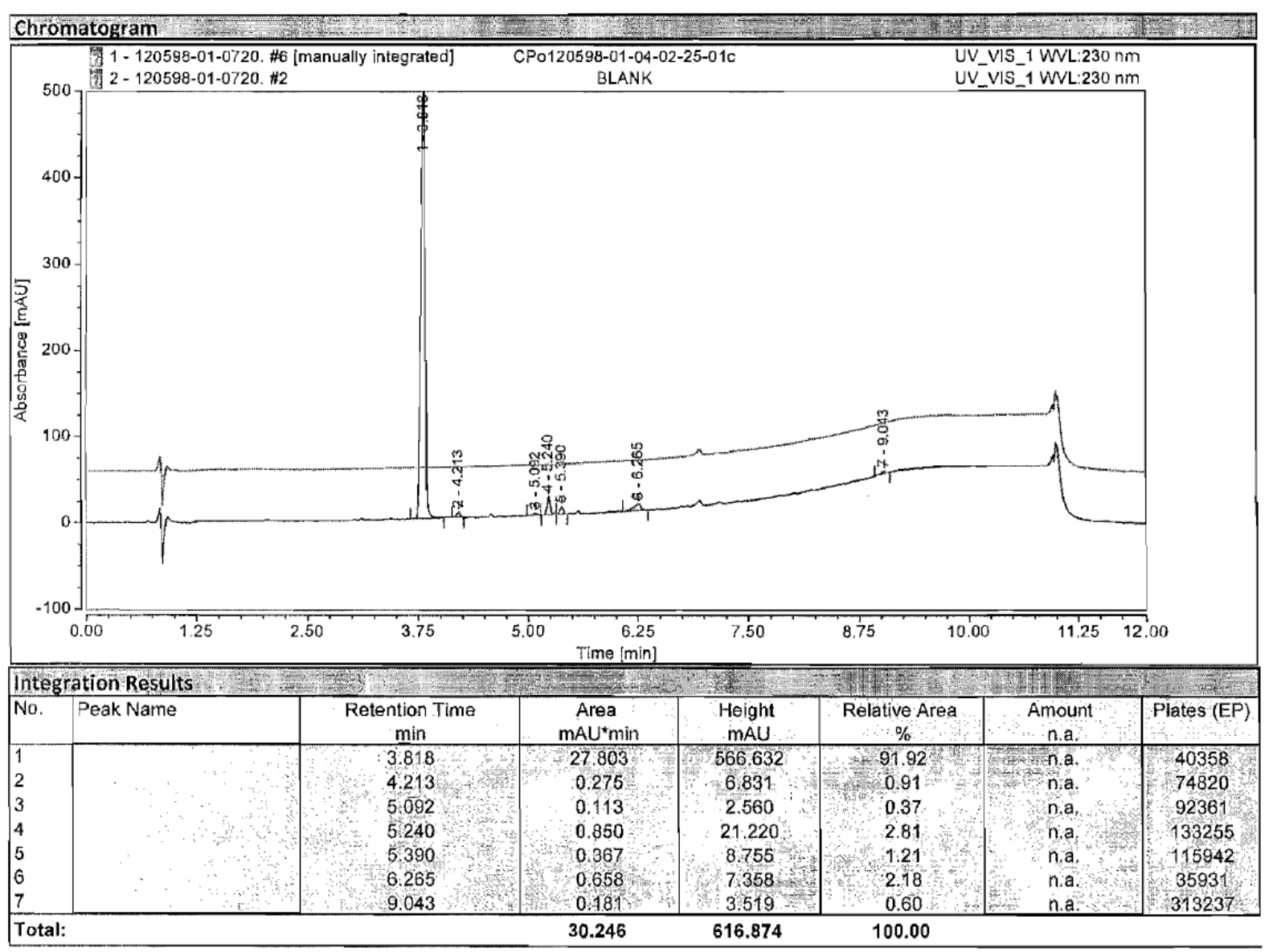


Quantitative ${ }^{1} \mathrm{H}$ NMR of compound 4:
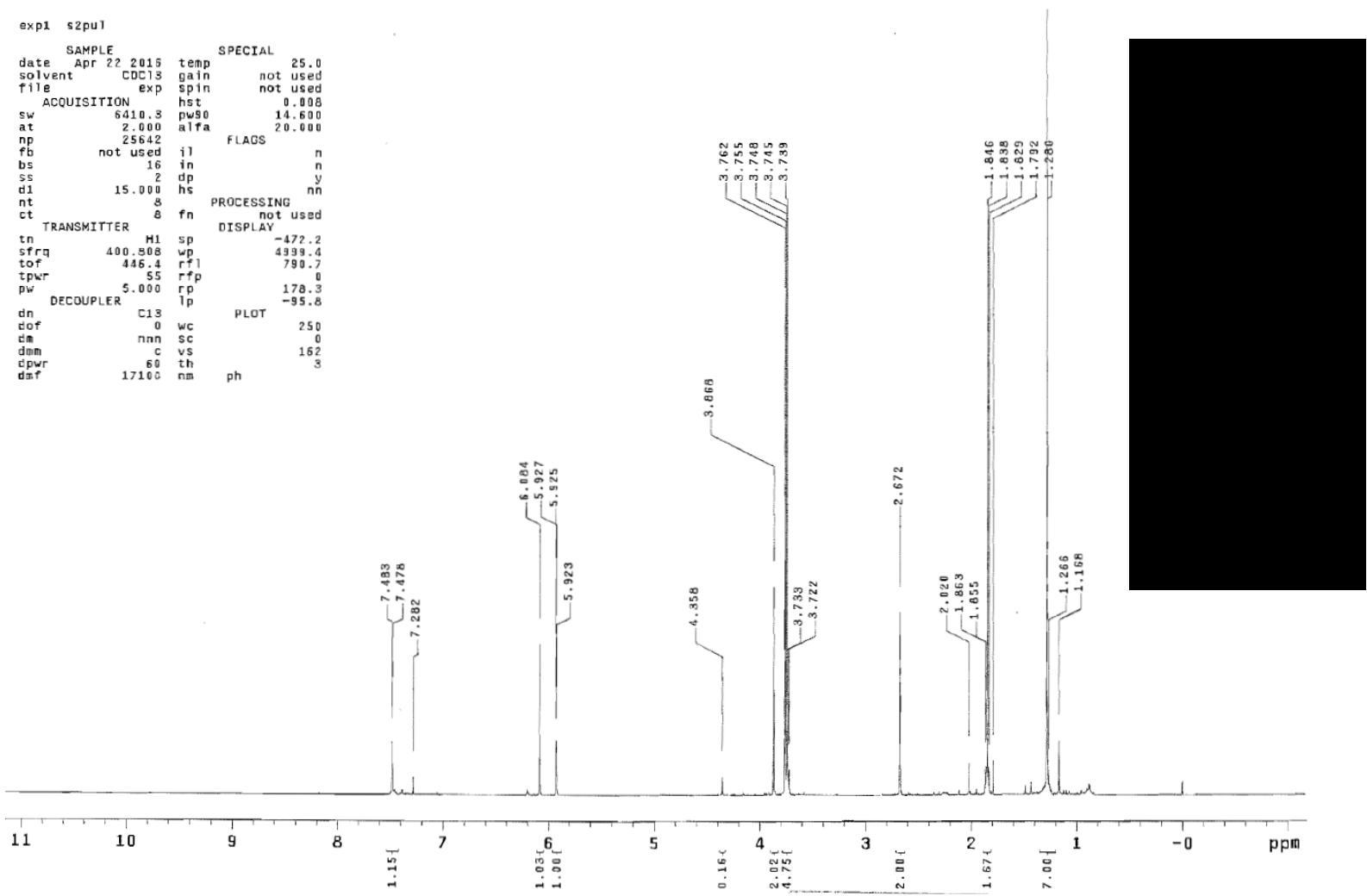

\begin{tabular}{|c|c|}
\hline Instrument & Varian $400 \mathrm{MHz}$ \\
\hline Solvent and concentration & $\mathrm{CDCl}_{3}$ \\
\hline Internal standard & $1,3,5$-trimethoxybenzene \\
\hline Nucleus and frequency in $\mathrm{MHz}$ & ${ }^{1} \mathrm{H}$ and $400.808 \mathrm{MHz}$ \\
\hline
\end{tabular}

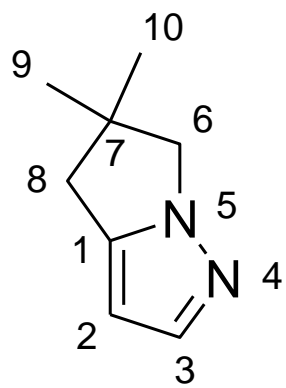

\begin{tabular}{|c|c|c|c|}
\hline${ }^{1} \mathrm{H}$ resonances $(\mathrm{ppm})$ & Number of $\mathrm{H}$ & Multiplicity & Atom \\
\hline 7.48 & 1 & $\mathrm{~d}$ & 3 \\
\hline 5.93 & 1 & $\mathrm{~d}$ & 2 \\
\hline 3.87 & 2 & $\mathrm{~s}$ & 6 \\
\hline 2.68 & 2 & $\mathrm{~s}$ & 8 \\
\hline 1.28 & 6 & $\mathrm{~s}$ & 9,10 \\
\hline
\end{tabular}

\begin{tabular}{|c|c|}
\hline Other ${ }^{1} \mathrm{H}$ resonances $(\mathrm{ppm})$ & Comment \\
\hline 0.00 & TMS \\
\hline 1.83 & unknown \\
\hline 7.28 & $\mathrm{CHCl}_{3}$ \\
\hline $6.08,3.75$ & $1,3,5$-trimethoxybenzene \\
\hline
\end{tabular}

Note: $s=$ singlet,$d=$ doublet,$t=$ triplet; $q=$ quartet,$m=$ multiplet,$d d=$ double doublet,$b=b r o a d$ 


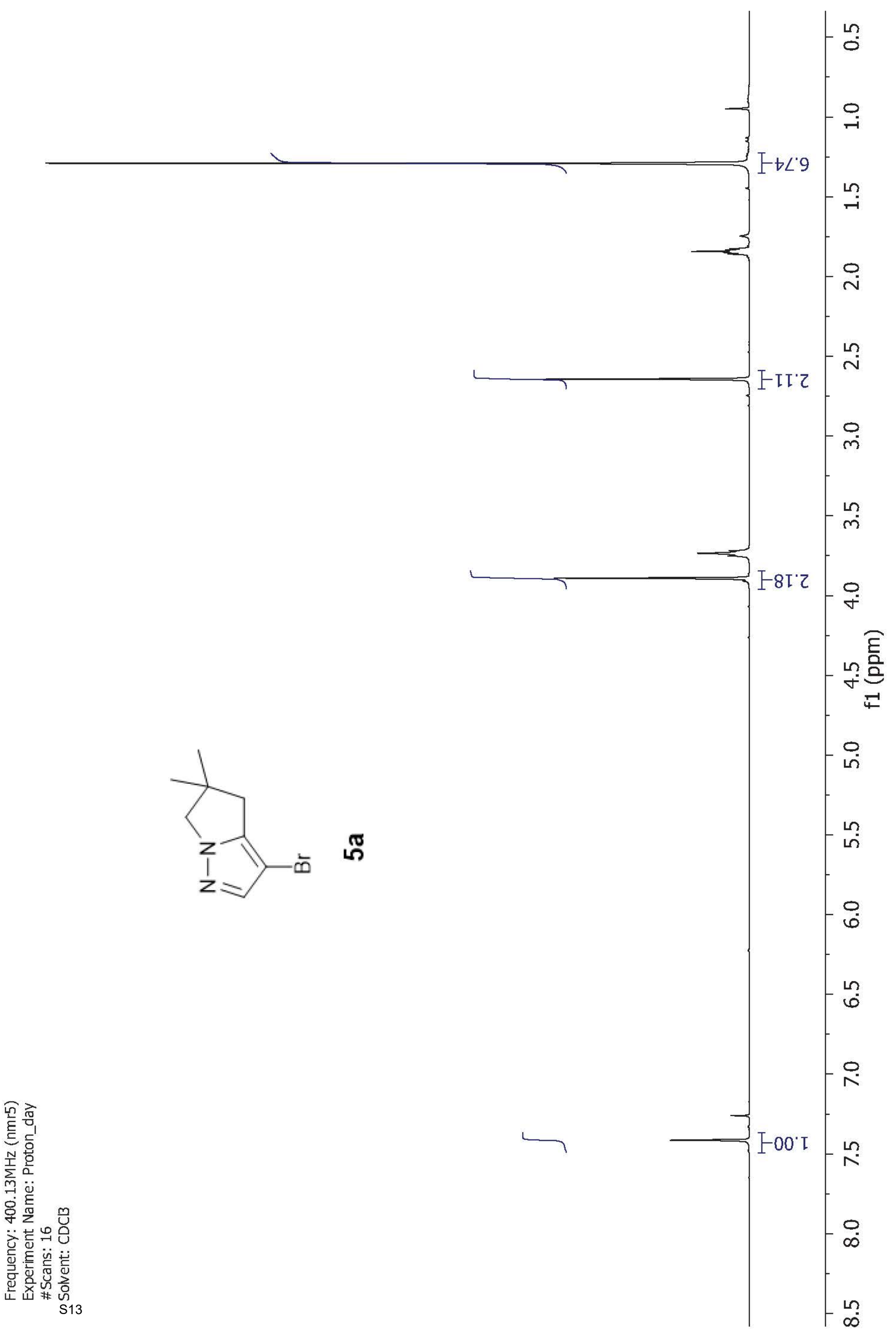




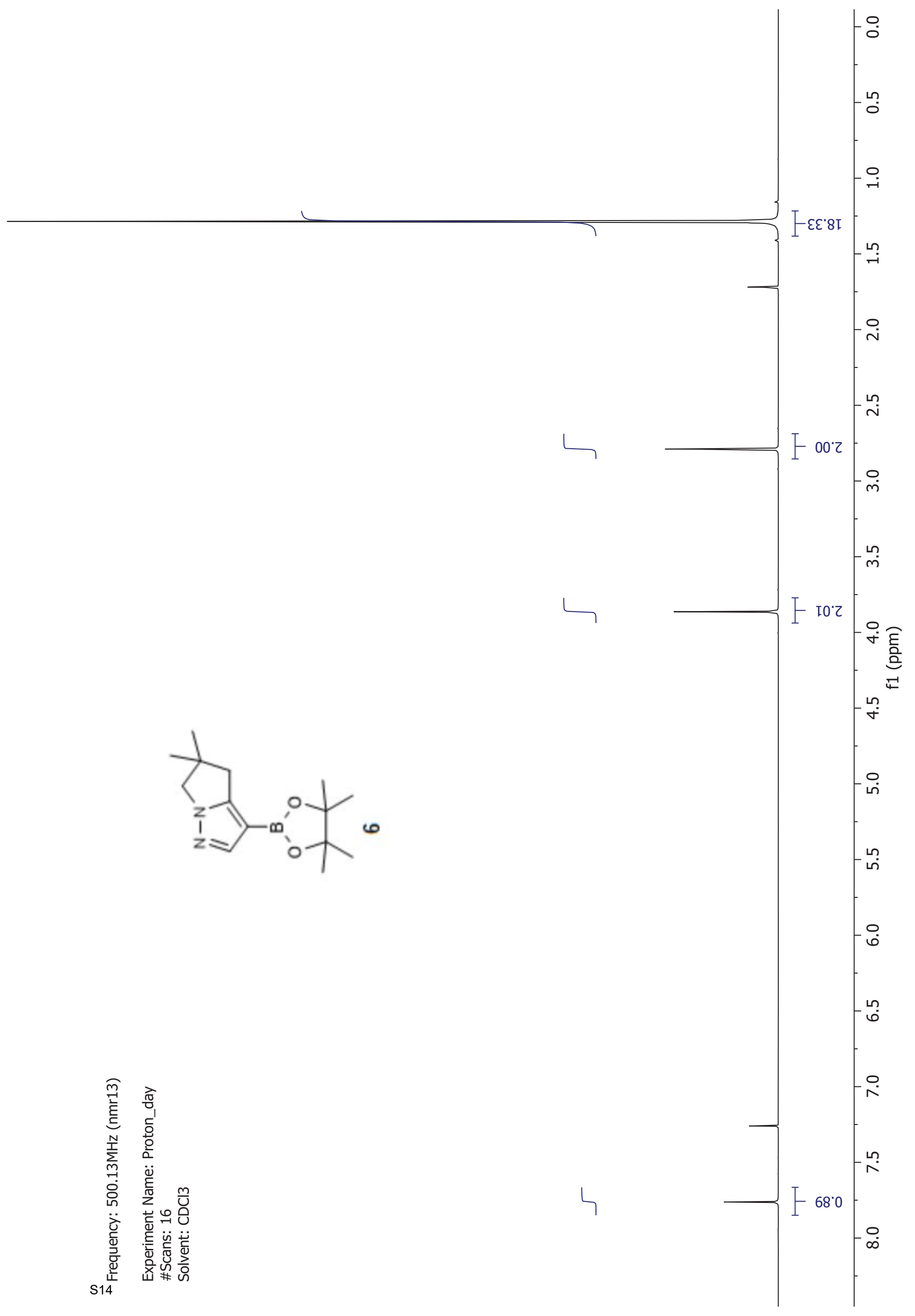




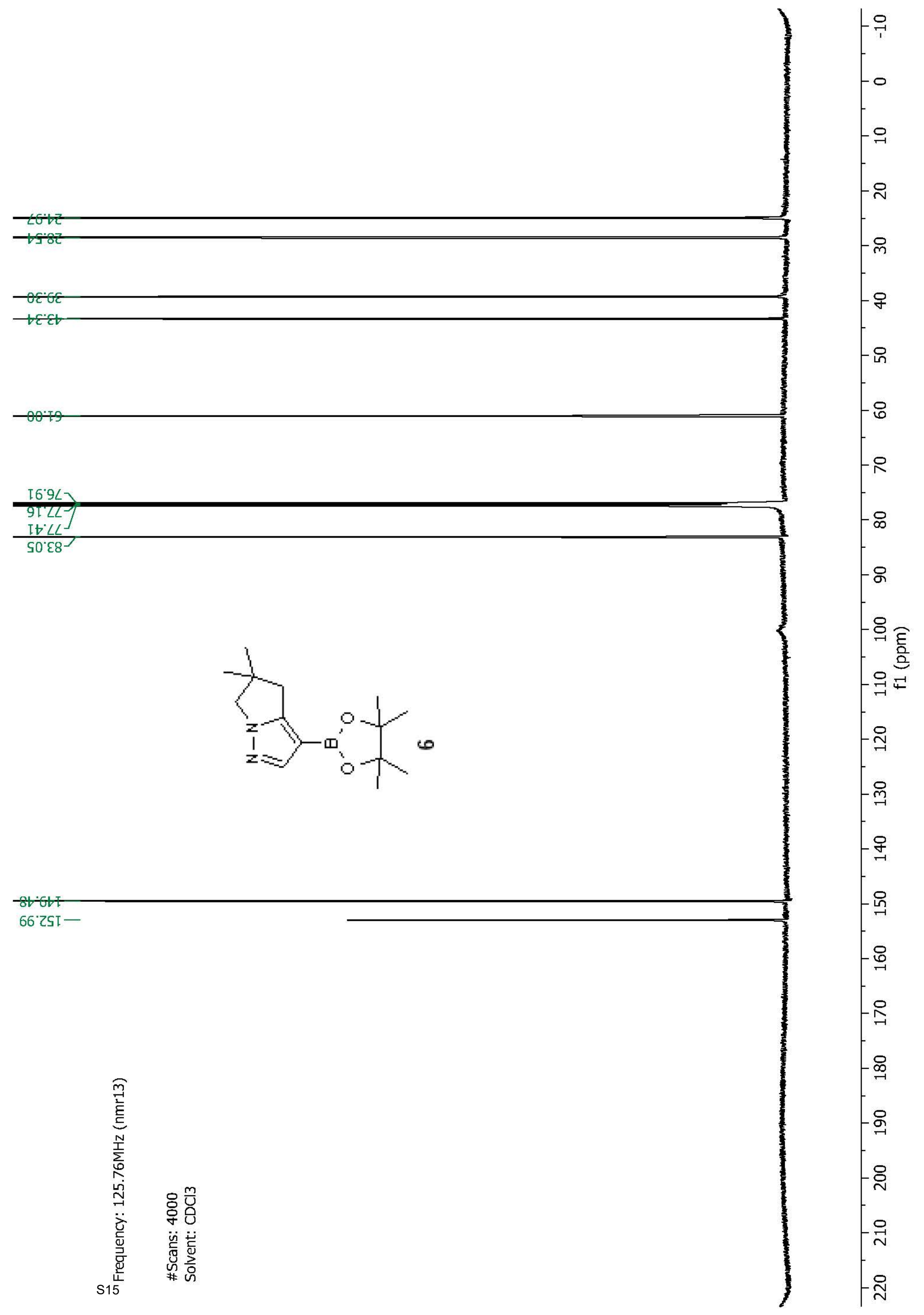


HPLC for compound 6

Conditions:

\begin{tabular}{|c|c|c|}
\hline Column: & \multicolumn{2}{|c|}{ YMC-Pack ProC18; 4.6 X 150mm, 3um } \\
\hline Column Temperature: & \multicolumn{2}{|l|}{$40^{\circ} \mathrm{C}$} \\
\hline Flow Rate: & \multicolumn{2}{|l|}{$1.0 \mathrm{~mL} / \mathrm{min}$} \\
\hline Injection Volume: & \multicolumn{2}{|l|}{$5 \mu \mathrm{L}$} \\
\hline Mobile phase A: & \multicolumn{2}{|l|}{ Water } \\
\hline Mobile phase B: & \multicolumn{2}{|l|}{ Acetonitrile } \\
\hline \multirow{5}{*}{ Gradient: } & Time & $\mathrm{B} \%$ \\
\hline & 0.0 & 10 \\
\hline & 15.0 & 90 \\
\hline & 15.1 & 10 \\
\hline & 20.0 & 10 \\
\hline Detection: & \multicolumn{2}{|l|}{$\mathrm{UV}$ at $220 \mathrm{~nm}$} \\
\hline Diluent: & \multicolumn{2}{|l|}{ Acetonitrile } \\
\hline Run time: & \multicolumn{2}{|l|}{$20 \mathrm{~min}$} \\
\hline
\end{tabular}

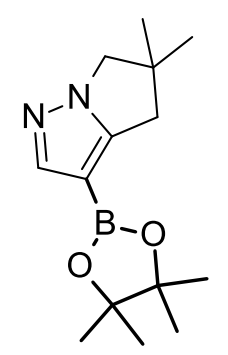

6 

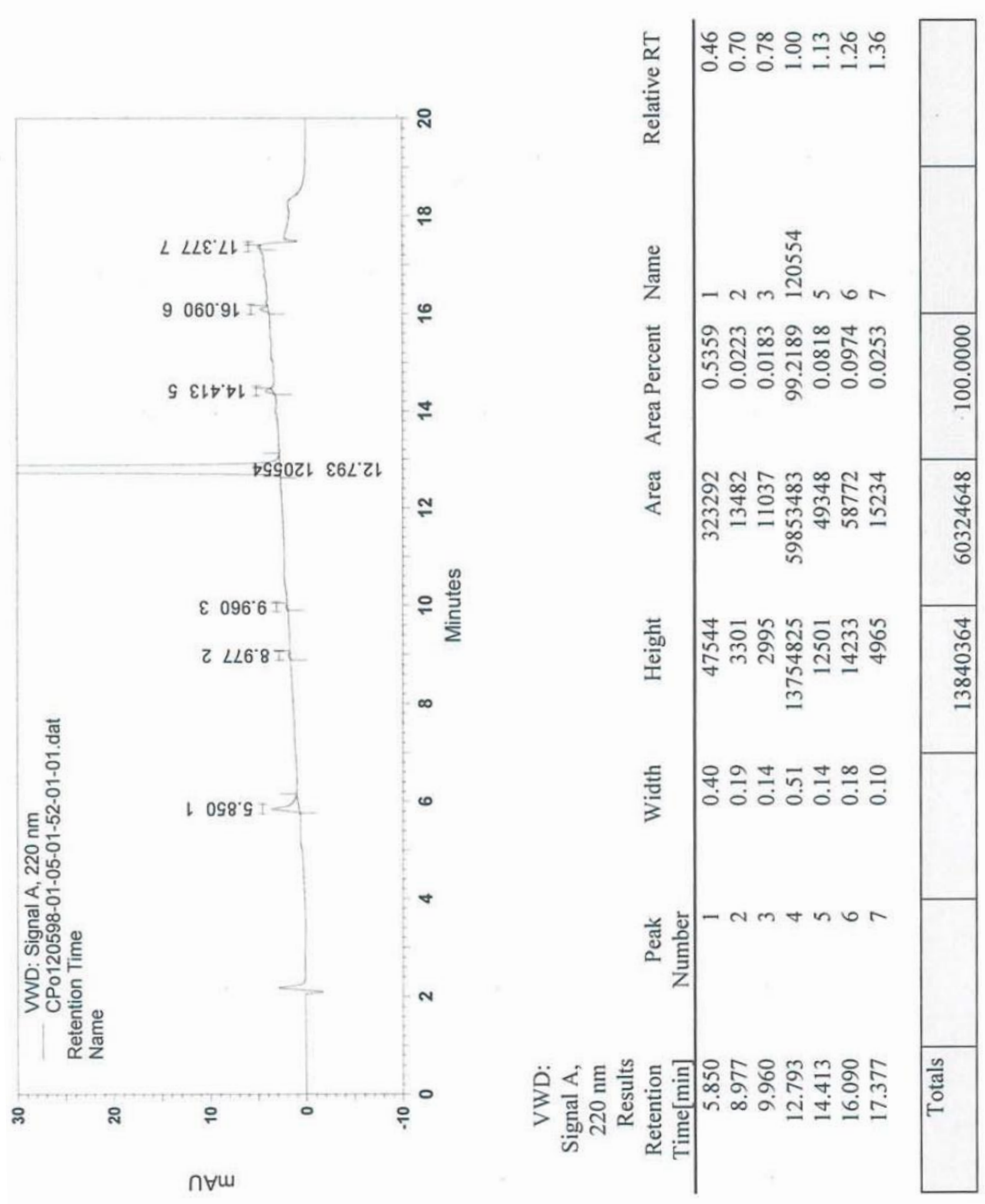
Phase Correction New - 0th: 2.6907 1st: -0.5000 Initial - 0th: 2.3600 1st: 0.0000 Diff - 0th: 0.33071 st: -0.5000 Number of Integrals: 3

$\begin{array}{llllll}\text { No } & \text { Value } & \text { Left Limit } & \text { Right Limit } & \text { Bias } & \text { Slope } \\ 1 & 100.0000 & 8.6133 & 8.3198 & -47,116.1260 & 81.1603 \\ 2 & 118.4019 & 8.1070 & 7.7475 & -7,632.8866 & 22.7282 \\ 3 & 118.1903 & 7.2159 & 6.8714 & -21,481.5373 & 61.5810\end{array}$

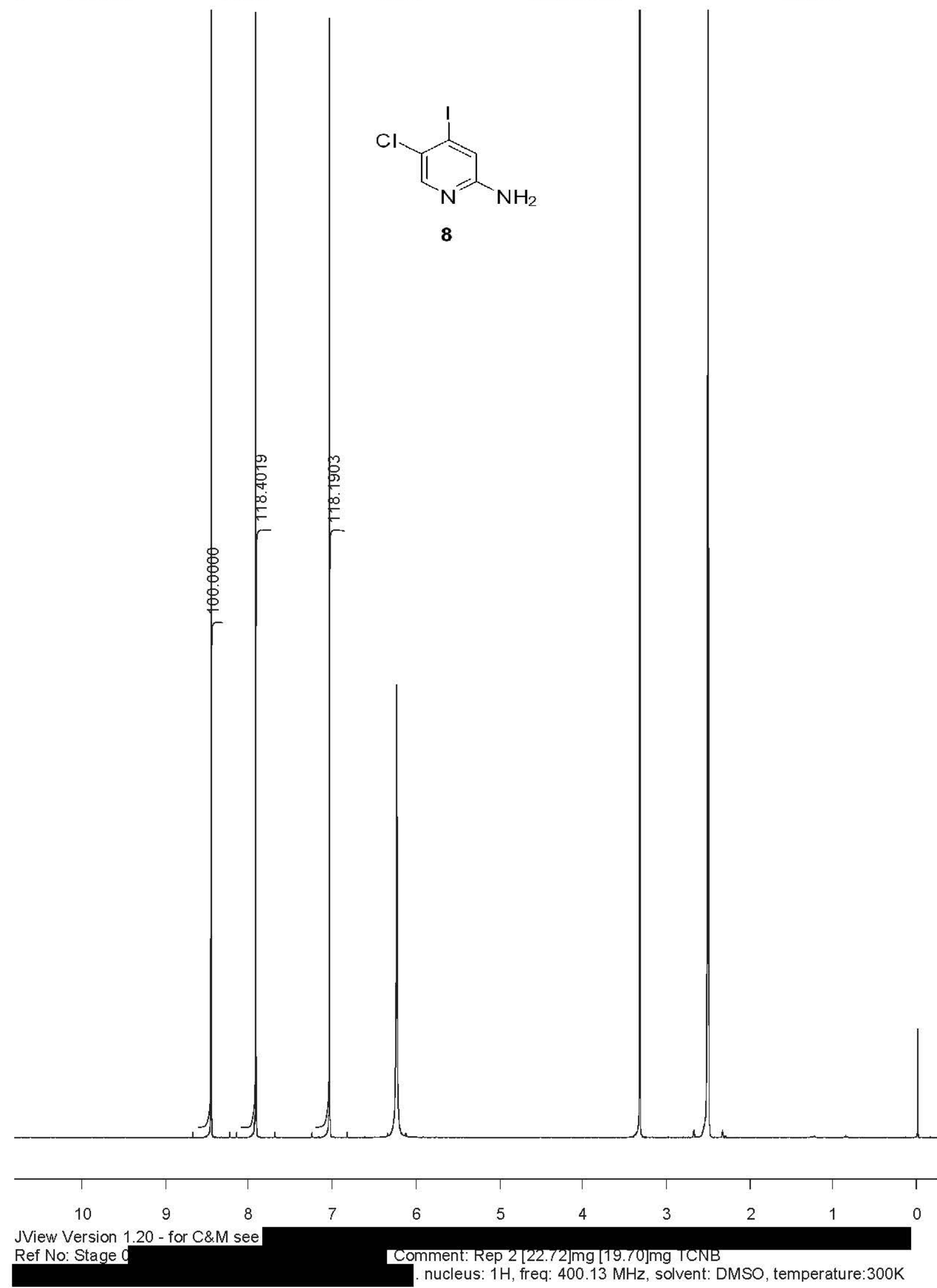




\section{Testing Report}

检测报告

\section{Compound 15}

Report ID 报告编号: AR-160323

\begin{tabular}{|c|c|c|c|c|}
\hline $\begin{array}{l}\text { Material Name } \\
\text { 物料名称 }\end{array}$ & AZM-242-0 & & $\begin{array}{l}\text { Material Code/ } \\
\text { Batch No. } \\
\text { 物料代码/批号 }\end{array}$ & AZM-242-0-A-1 \\
\hline $\begin{array}{l}\text { Request } \\
\text { 测试目的 }\end{array}$ & \Original 初检 & \multicolumn{3}{|c|}{$\square$ Retest 复验 } \\
\hline $\begin{array}{l}\text { Received } \\
\text { Date } \\
\text { 接检日期 }\end{array}$ & 2016.04 .25 & & $\begin{array}{l}\text { Retest Date } \\
\text { 复验期 }\end{array}$ & 2017.04 .22 \\
\hline
\end{tabular}

\begin{tabular}{|c|c|c|c|c|c|}
\hline $\begin{array}{l}\text { Test } \\
\text { 测试 }\end{array}$ & $\begin{array}{l}\text { Method No. } \\
\text { 检测方法 }\end{array}$ & \multicolumn{2}{|c|}{$\begin{array}{l}\text { Specification } \\
\text { 标准 }\end{array}$} & $\begin{array}{l}\text { Results } \\
\text { 结果 }\end{array}$ & $\begin{array}{l}\text { Confor } \\
\mathrm{m} \\
\text { 结果确认 }\end{array}$ \\
\hline Appearance & MTH-GEN-012 & \multicolumn{2}{|c|}{ Report result } & White solid & YES \\
\hline \multirow{2}{*}{ Identification } & MTH-GEN-008 & ${ }^{1} \mathrm{H}$ NMR & $\begin{array}{c}\text { Consistent with } \\
\text { structure }\end{array}$ & $\begin{array}{c}\text { Consistent with } \\
\text { structure }\end{array}$ & \multirow{2}{*}{ YES } \\
\hline & MTH-GEN-011 & LCMS & $\begin{array}{c}\text { Consistent with } \\
\text { structure }\end{array}$ & $\begin{array}{l}\text { Consistent with } \\
\text { structure }\end{array}$ & \\
\hline \multirow{3}{*}{$\begin{array}{l}\text { Purity by } \\
\text { HPLC } \\
\text { (\%Area) }\end{array}$} & & $\begin{array}{c}\text { Area HPLC } \\
\text { purity }\end{array}$ & MT 98\% & $100 \%$ & \multirow{3}{*}{ YES } \\
\hline & & $\begin{array}{l}\text { Cis isomeric } \\
\text { purity }\end{array}$ & MT 98\% & $100 \%$ & \\
\hline & & $\begin{array}{l}\text { Enantiomeric } \\
\text { purity }\end{array}$ & MT 99\% & $100 \%$ & \\
\hline $\begin{array}{l}\text { Single } \\
\text { impurity }\end{array}$ & & \multicolumn{2}{|c|}{ NMT $0.5 \%$} & Not detected & YES \\
\hline $\begin{array}{l}\text { Assay by } \\
{ }^{1} \mathrm{H} \text { NMR }\end{array}$ & & \multicolumn{2}{|c|}{ NLT $95.0 \%$} & $98.9 \%$ & YES \\
\hline
\end{tabular}

The results comply with above specifications.

检验结果符合质量标准。 Y Y es $\square$ No

报告人旧期

Reported by/Date

审核人/日期

Reviewed by/Date

批准人/日期

Approved by/Date 


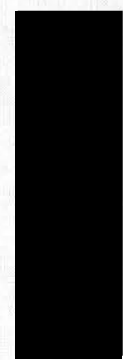

$\triangle 20^{\circ}$

Z9.'

$19 L^{\circ}$

$28 L^{\circ}$

L61 1

ZLट'L

$212 !$

$62 Z L$
$\angle 8 Z L$

ZOE'

LLE'L

$\varepsilon \varepsilon \varepsilon !$

乙૪६

OSE :

$98 \varepsilon$ เ

เLザ

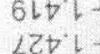

$\varepsilon \nabla \nabla \downarrow$

ZSt: L

0971

678 '

$\angle S^{\circ} \mathrm{L}$

$998^{\circ} \mathrm{L}$

$\varepsilon \angle 8^{\circ} \mathrm{L}$

$288^{\circ} \mathrm{L}$

$168^{\circ} \mathrm{L}$

$006 \%$

$606 \%$

9\&6 ᄂ

OS6 L

$\varepsilon 86 \downarrow$

$986 \mathrm{~L}$

Gllz-

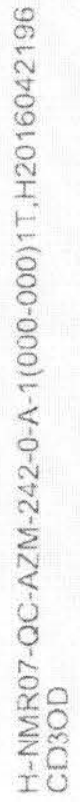

6เ। 2

ยZเ乙-

9ㄴ? 2

OSLZ

$\triangle S+Z$

$\varepsilon \angle \varepsilon^{\prime} Z$

ว $8 \varepsilon^{\prime 2} 2$

96ह Z

DOD'

ELt

9ztz

$\nabla \varepsilon \nabla Z$

टวย'

वृह $\varepsilon$

०ะย $\varepsilon-$

$\triangleright \varepsilon \varepsilon^{\circ} \varepsilon-$

टहE $\varepsilon$

เ99.

$1 \angle 9^{\circ} \varepsilon$

$189^{\circ} \varepsilon$

$169^{\circ} \varepsilon-$
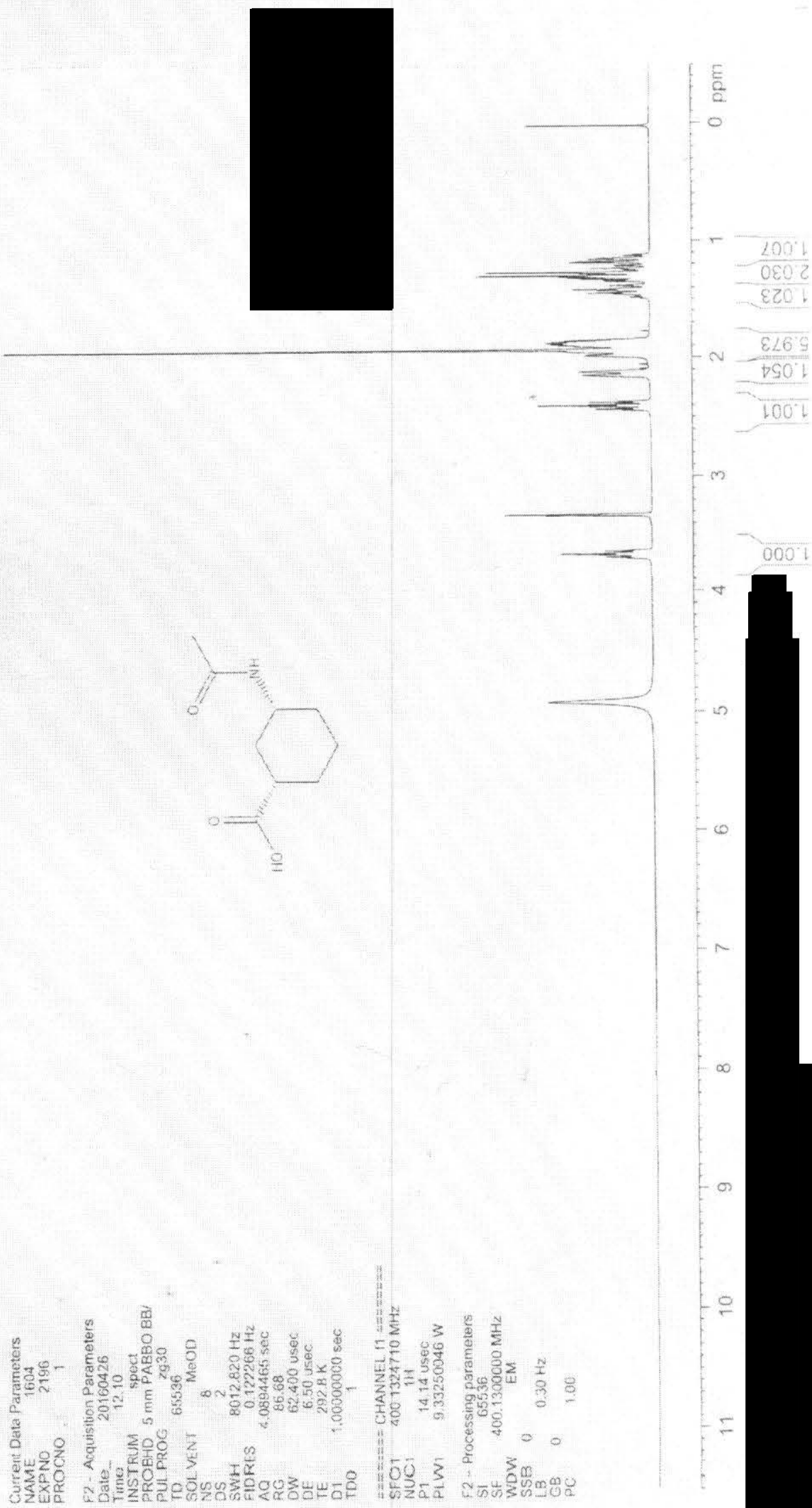

DSO

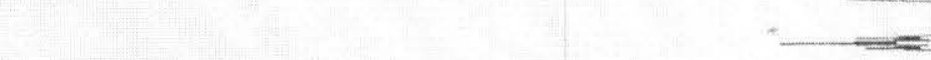

(

(2)

x

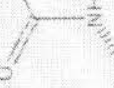

$0+$

$\infty$

$\infty$

4

$+$

$-\infty$

-

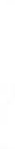

o

$-\frac{0}{-}$

N

$=$

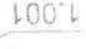

.

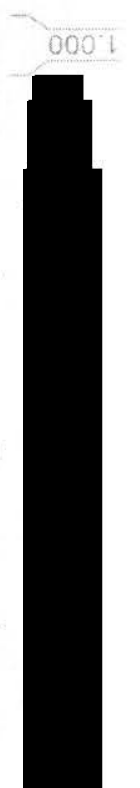

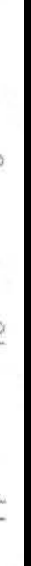

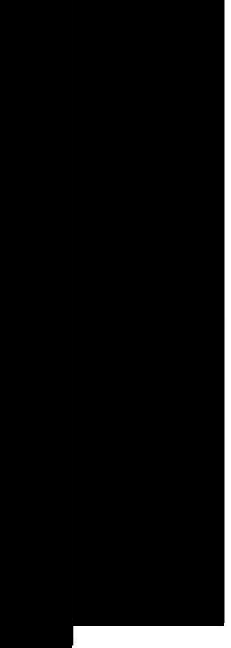




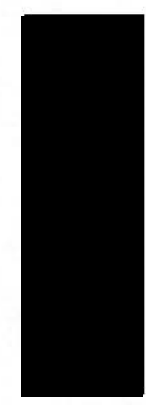

$$
\angle 100
$$

OSL!

$69 L^{\circ}$

$081 \%$

OL2.

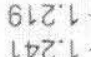

$\downarrow \angle Z \downarrow-\frac{1}{F}$

ट० $!$

GLE

$\varepsilon \varepsilon \varepsilon$

$6 \varepsilon \varepsilon$ '

$\angle \nabla E^{\prime} L-M$

Z8E L

LOT'L

SLt

हट†!

$8 \nabla t \downarrow$

$990^{\circ} L$

St8:

$658 \mathrm{~L}$

6981

$988^{\circ} \mathrm{L}$

$\nabla 68^{\circ} \mathrm{L}$

$\nabla 06$ '

$986 !$

1861

6412

EZL

LSL'z-

$\nabla G+2$

$09 \varepsilon^{\prime} Z$ -

$89 \varepsilon^{\prime} 2-$

$\angle L E^{\prime} Z$

$06 \varepsilon$ ' 2 -

$66 \varepsilon^{2} Z$

8002

0ZரZ

6てヤて

$8 \varepsilon+2$

乙टह'

ตฉะ' $\varepsilon$

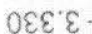

$\varepsilon \varepsilon \varepsilon^{\prime} \varepsilon$

$\angle \mathcal{E} \mathcal{E}^{\prime} \mathcal{E}$

$6 \triangleright 9^{\circ} \varepsilon$

$699^{\circ} \varepsilon$

$699^{\circ} \varepsilon-$

$6 \angle 9^{\prime} \varepsilon$

$889^{\circ} \varepsilon$

$669^{\circ} \varepsilon$

$80 \angle \varepsilon$

8167
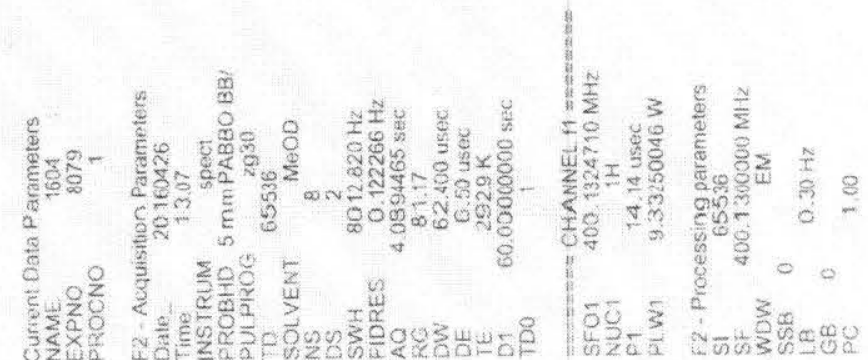


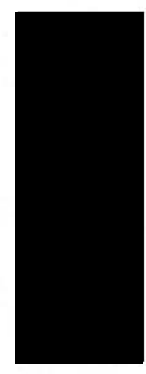

6Dt'

0812

$881 ' 1$

0121

$1+21$

$4 \angle Z$ '

$\checkmark 82$

ZOE L

SLE:

हEह

$9 \triangleright \varepsilon$ ।

ट8\&

LOt L

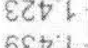

$807 \div$

9St L

$968^{\circ} \mathrm{h}$

2981

098 .

$698^{\circ}$

$988 \mathrm{~L}$

$\square 681$

806 L

$986 \mathrm{~L}$

$186 \downarrow$

6.12-

E己LZ-

LDL'Z

LSIZ

$69 \varepsilon 乙$

8982

$\angle L E^{\prime} Z$

$06 \varepsilon 2-$

$86 \varepsilon z$

2002

$0 z+2$

$62+2$

$8 \varepsilon \nabla Z$

टटह

9टह'

०८ह' $\varepsilon$

$\nabla \varepsilon \varepsilon \varepsilon$

LहE \&

$6 \nabla 9 \varepsilon$

$659 \varepsilon$

$699^{\circ} \varepsilon$

$6 \angle 9^{\circ} \&$

$889^{\circ} \varepsilon$

$669^{\circ} \varepsilon$

$80 \angle \varepsilon-$

0265
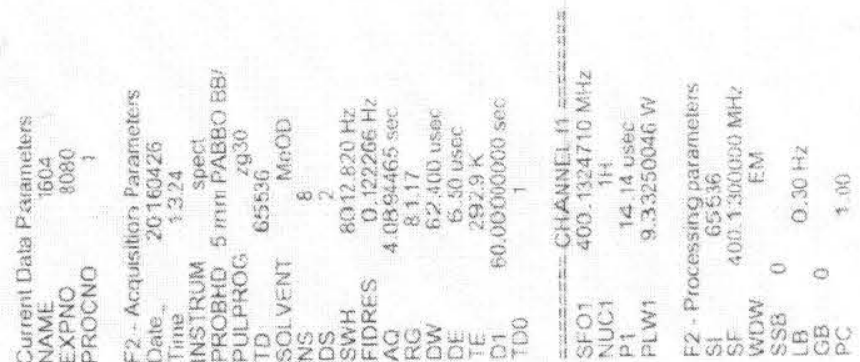

$\infty$

운 


\section{Assay of AZM-242-0-A-1 by H-NMR}

1. Standards, Reagents and Materials

1.1. Solvent: $\mathrm{CD}_{3} \mathrm{OD}, 99.8$ atom\% D, contains $0.05 \%(\mathrm{v} / \mathrm{v})$ TMS, Lot\# PR-26856/060515ME1

1.2. Internal standard: $2,3,5,6$-tetrachloronitrobenzene(TCNB), $>98.0 \%$, HPLC grade Manufactured by: Tokyo Chemical Industry Co., Ltd. Lot \#:Z7AKG-GI. Exp. Date: 08Aug2017.

1.3. Sample: AZM-242-0-A-1. Manufacture date:2016.04.23

2. Instrumentation

2.1. Bruker AV $400 N M R$ spectrometer. NMR-07

2.2. B-ACS 60 Autosampler

2.3. Mettler Toledo Balance XS105, ID: BAL-09.

3. H-NMR spectrum collection parameters

3.1. NS: 8

3.2. DS: 2

3.3. $\mathrm{SWH}: 8012.820 \mathrm{~Hz}$

3.4. DW: 62.400 usec

3.5. DE: 6.50usec

3.6. TE: $292.9 \mathrm{~K}$

3.7. D1: $60.00000000 \mathrm{sec}$

3.8. TDO: 1

4. Example spectrum

4.1. Sample with internal standard

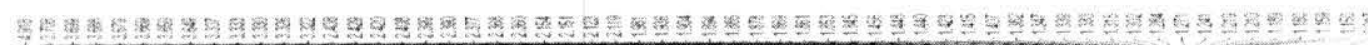

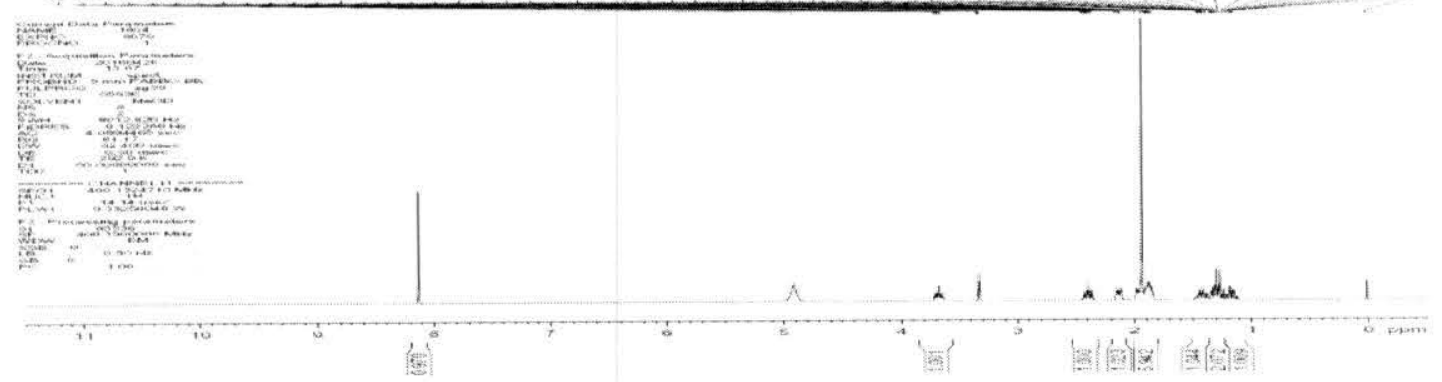



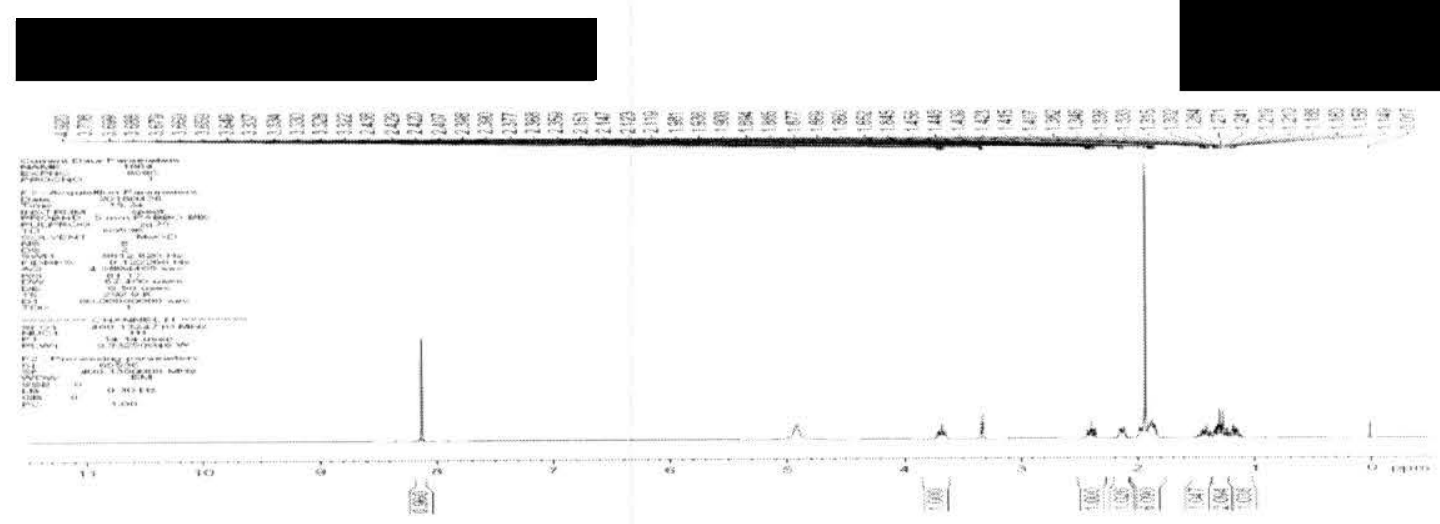

5. Sample Preparation:

5.1. Sample-1: Accurately weighed $27.37 \mathrm{mg}$ of TCNB and $20.00 \mathrm{mg}$ of AZM-242-0-A-1 into a NMR tube. Dissolved with $0.6 \mathrm{ml}$ of $\mathrm{CD}_{3} \mathrm{OD}$. Mixed thoroughly.

5.2. Sample-2: Accurately weighed $28.09 \mathrm{mg}$ of TCNB and $20.44 \mathrm{mg}$ of AZM-242-0-A-1 into a NMR tube. Dissolved with $0.6 \mathrm{ml}$ of $\mathrm{CD}_{3} \mathrm{OD}$. Mixed thoroughly.

6. Calculations by H-NMR

Assay \% $=\frac{W t(S t d) \times N[H](S t d) \times M(S p l) \times n[H](S p l)}{W t(s p l) \times n[H](S t d) \times M(S t d) \times N[H](S p l)} \times P \times 100 \%$

Where:

$W t(S t d)=$ Weight of internal standard $(\mathrm{mg})$

$W t(S p l)=$ Weight of sample $(\mathrm{mg})$

$\mathrm{N}[\mathrm{H}](\mathrm{Std})=$ Theoretical $[\mathrm{H}]$ value of $\mathrm{CH}$ at $8.1 \mathrm{ppm}$ in internal standard

$n[H](S t d)=$ Actual $[\mathrm{H}]$ value of $\mathrm{CH}$ at $8.1 \mathrm{ppm}$ in internal standard

$\mathrm{N}[\mathrm{H}](\mathrm{Spl})=$ Theoretical $[\mathrm{H}]$ value of $\mathrm{CH}$ at $3.7 \mathrm{ppm}$ and $2.4 \mathrm{ppm}$ in sample

$n[H](S p l)=$ Actual $[\mathrm{H}]$ value of $\mathrm{CH}$ at $3.7 \mathrm{ppm}$ and $2.4 \mathrm{ppm}$ in sample

$M(S p l)=$ Molecular weight of sample (185.22)

$M($ Std $)=$ Molecular weight of internal standard (260.89)

$P=$ Purity of internal standard $(98.0 \%)$

7. Result

\begin{tabular}{|c|c|c|c|c|c|c|c|c|}
\hline \multirow{2}{*}{$\begin{array}{l}\text { Sample } \\
\text { name }\end{array}$} & \multirow{2}{*}{$\begin{array}{c}\text { Weight of } \\
\text { internal } \\
\text { standard(mg) }\end{array}$} & \multirow{2}{*}{$\begin{array}{l}\text { Weight of } \\
\text { sample } \\
\text { (mg) }\end{array}$} & \multirow{2}{*}{$\begin{array}{c}\text { Actual } \\
\text { value of [H] } \\
\text { of STD } \\
8.1 \mathrm{ppm} \\
\end{array}$} & \multicolumn{2}{|c|}{$\begin{array}{c}\text { Actual value of }[\mathrm{H}] \\
\text { of SPL }\end{array}$} & \multicolumn{2}{|c|}{ Assay $(\% w / w)$} & \multirow{2}{*}{$\begin{array}{l}\text { Avg. } \\
\text { Assay } \\
(\% w / w)\end{array}$} \\
\hline & & & & $3.7 \mathrm{ppm}$ & $2.4 \mathrm{ppm}$ & $3.7 \mathrm{ppm}$ & $2.4 \mathrm{ppm}$ & \\
\hline \multirow{2}{*}{$\begin{array}{c}\text { AZM-242- } \\
0-A-1\end{array}$} & 27.37 & 20.00 & 0.970 & 1.001 & 1.000 & 98.26 & 98.16 & \multirow{2}{*}{98.9} \\
\hline & 28.09 & 20.44 & 0.960 & 1.000 & 1.000 & 99.60 & 99.60 & \\
\hline
\end{tabular}


8. Conclusion

The average assay of AZM-242-0-A-1 was $98.9 \%$.
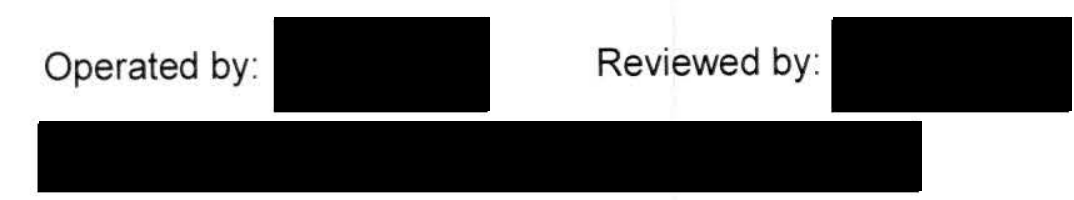


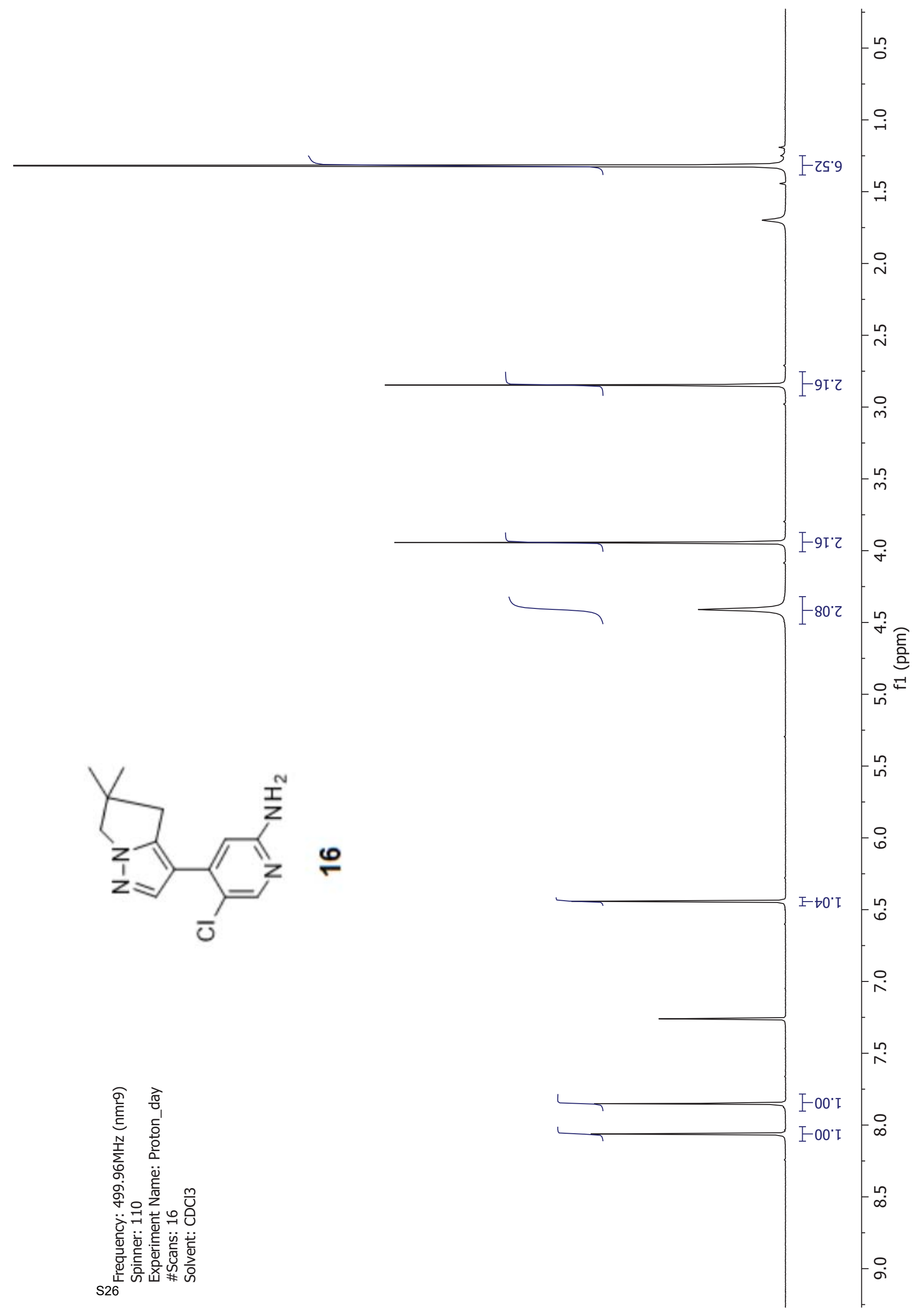


98 $\angle O I-$ IOZII乙E'6I I-

0ย'功】 S8. ZЬT $\rightarrow I^{\circ} b t 5$ $\rightarrow I \cdot 8 t I-$ $90^{\circ} \angle S I-$
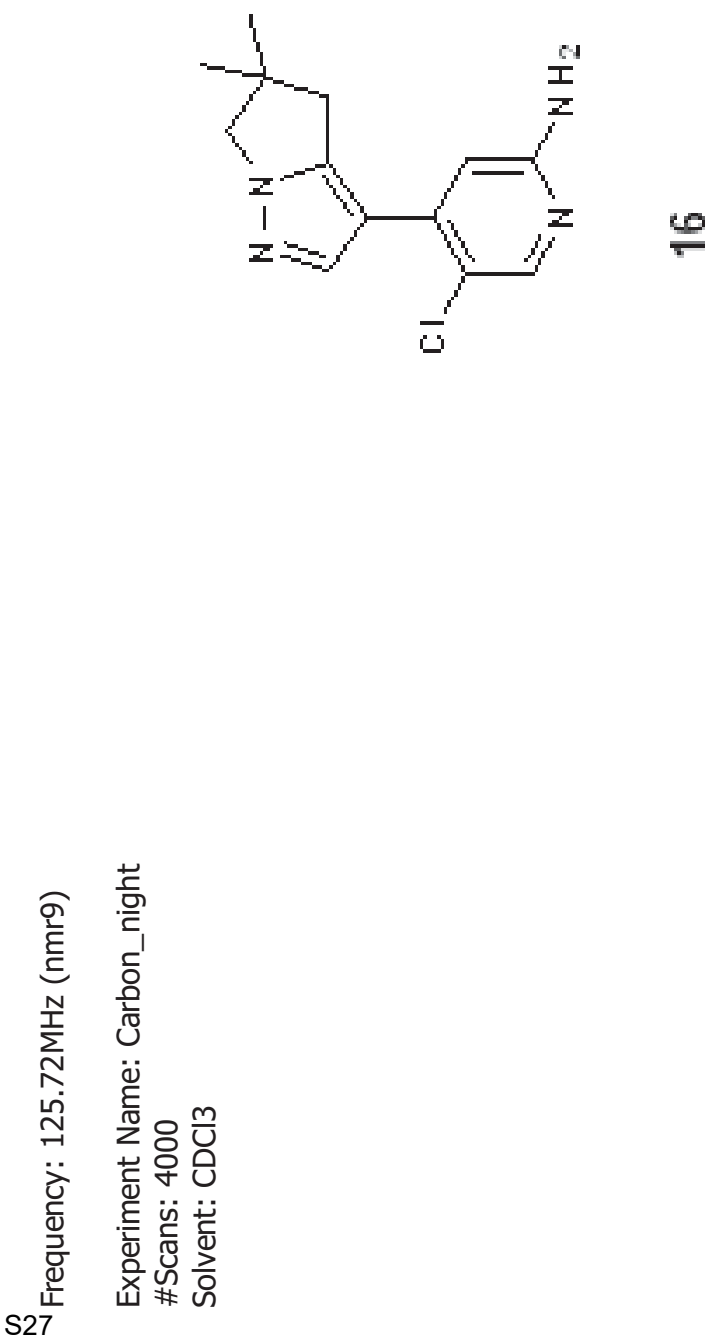

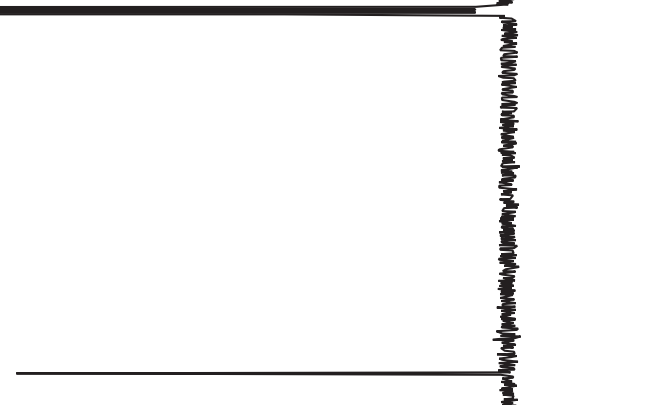




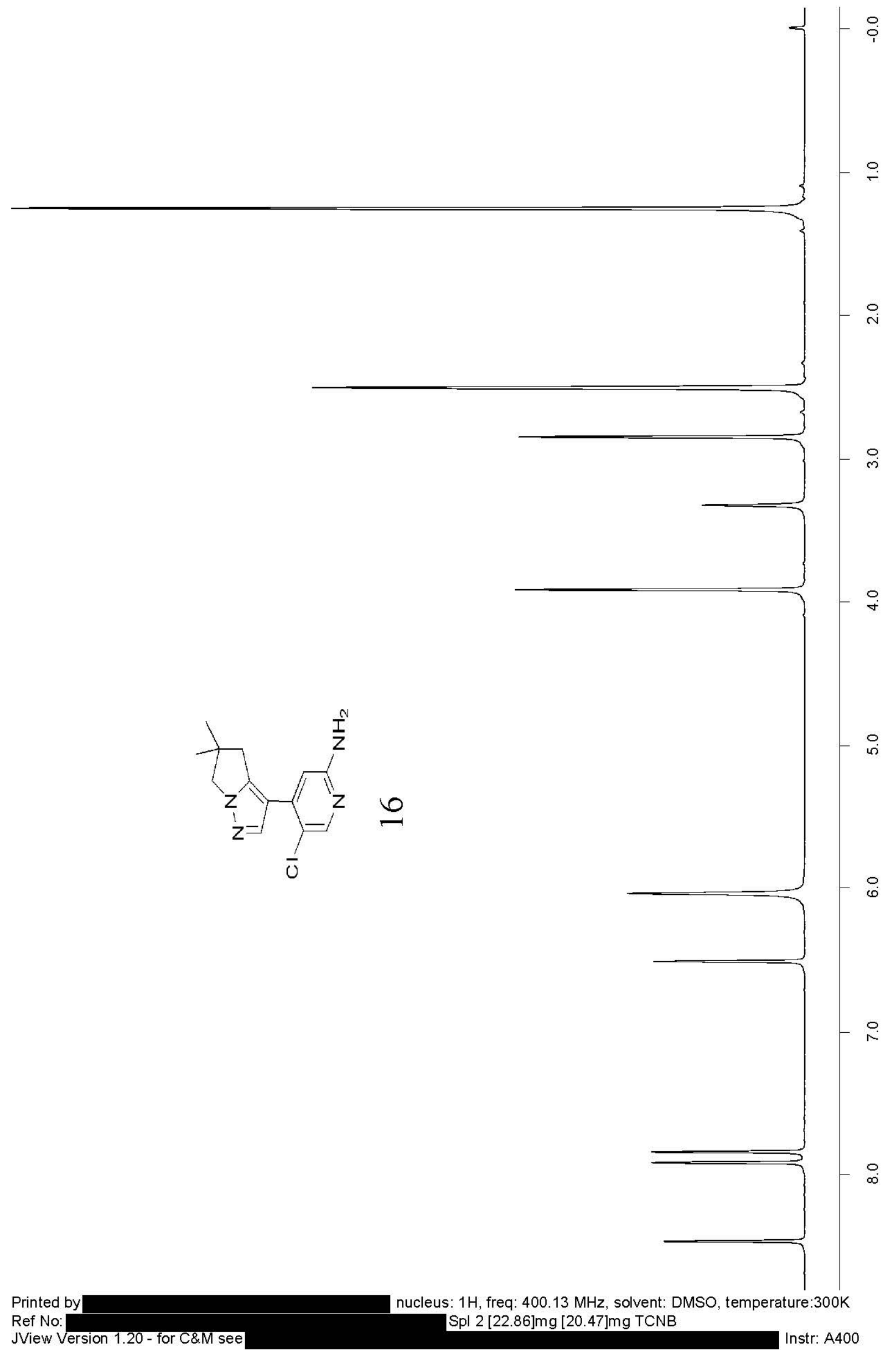




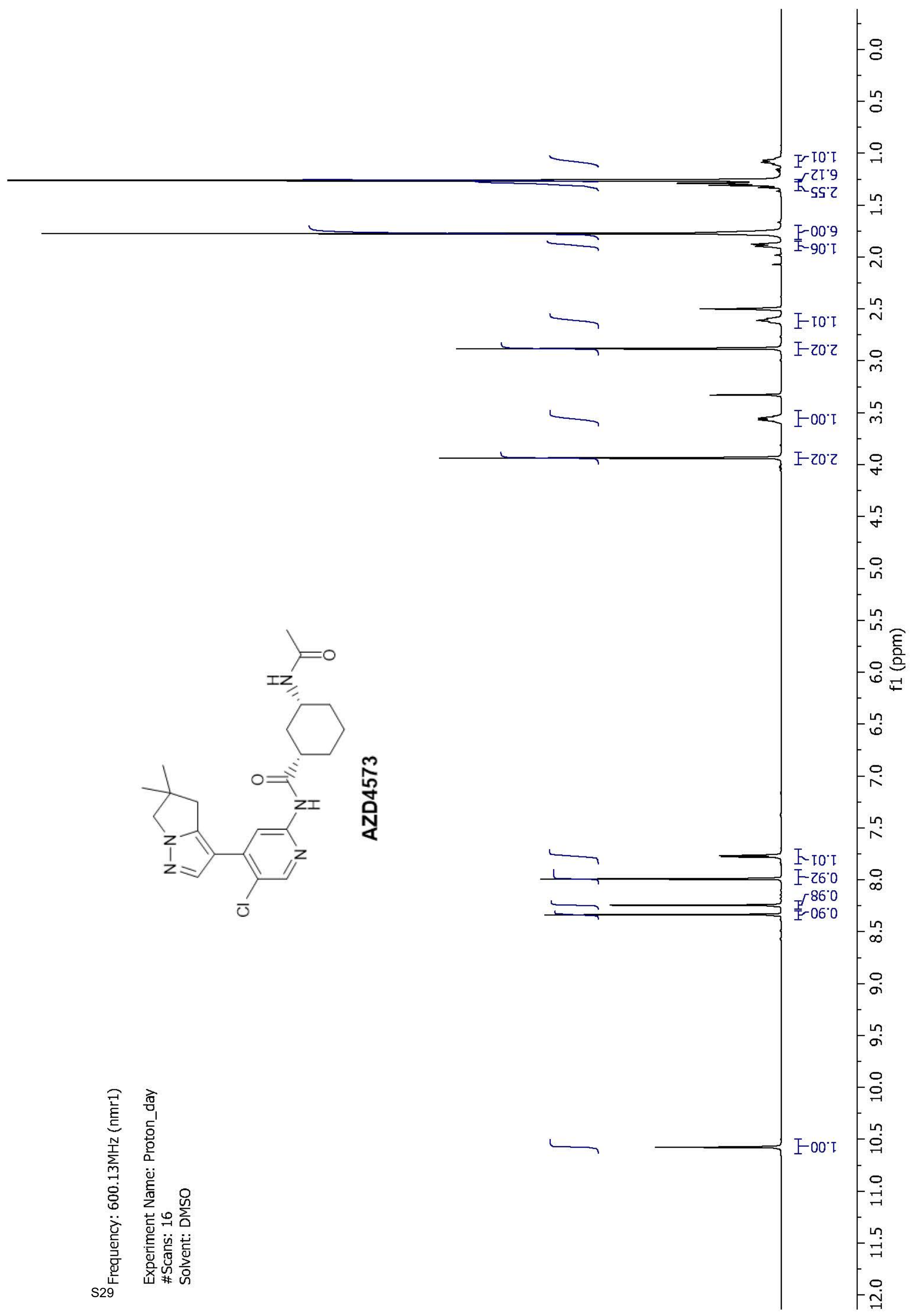


E0.tIT-

60'ZII

ย8 เIZI-

6ع.0tI88. It I TL'th厂

E0.8t 60.'ST-
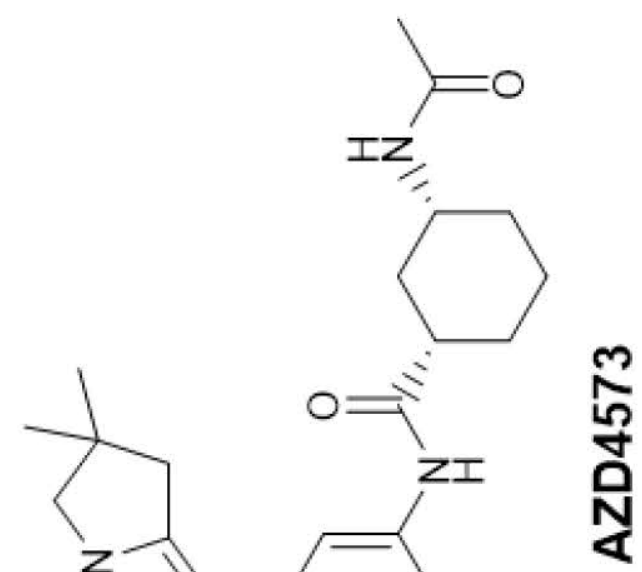
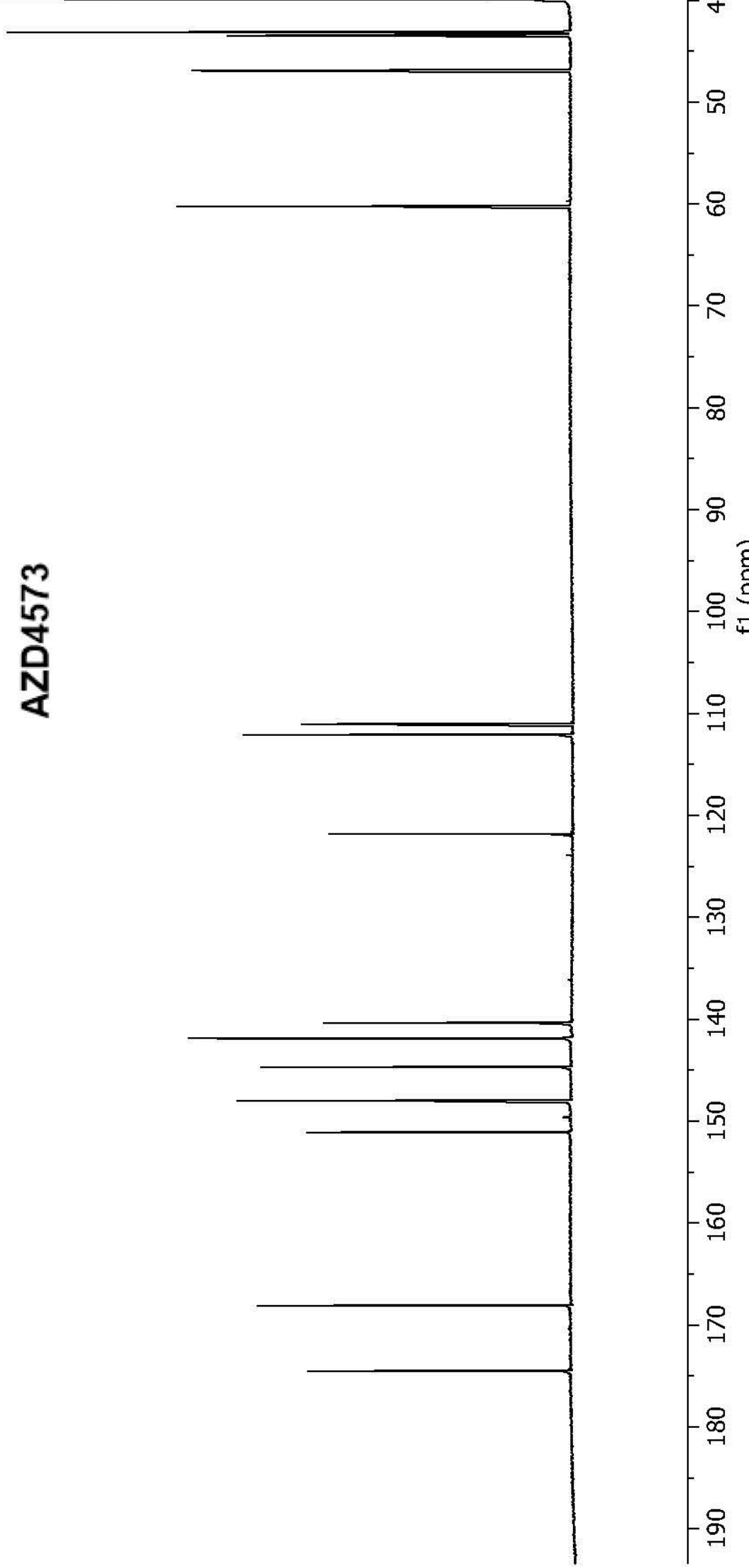